\title{
Curcumin Induces Nrf2 Nuclear Translocation and Prevents Glomerular Hypertension, Hyperfiltration, Oxidant Stress, and the Decrease in Antioxidant Enzymes in 5/6 Nephrectomized Rats
}

\author{
Edilia Tapia, ${ }^{1}$ Virgilia Soto, ${ }^{2}$ Karla Mariana Ortiz-Vega, ${ }^{1}$ \\ Guillermo Zarco-Márquez, ${ }^{3}$ Eduardo Molina-Jijón, ${ }^{3}$ Magdalena Cristóbal-García, ${ }^{1}$ \\ José Santamaría, ${ }^{1}$ Wylly Ramsés García-Niño, ${ }^{3}$ Francisco Correa, ${ }^{4}$ \\ Cecilia Zazueta, ${ }^{4}$ and José Pedraza-Chaverri ${ }^{3}$ \\ ${ }^{1}$ Renal Pathophysiology Laboratory, Department of Nephrology, Instituto Nacional de Cardiología Ignacio Chávez, \\ 14080 Mexico City, DF, Mexico \\ ${ }^{2}$ Department of Pathology, Instituto Nacional de Cardiología Ignacio Chávez, 14080 Mexico City, DF, Mexico \\ ${ }^{3}$ Department of Biology, Facultad de Química, Universidad Nacional Autónoma de México (UNAM), 04510 Mexico City, DF, Mexico \\ ${ }^{4}$ Department of Biochemistry, Instituto Nacional de Cardiología Ignacio Chávez, 14080 Mexico City, DF, Mexico
}

Correspondence should be addressed to Edilia Tapia, ediliatapia@hotmail.com

Received 4 May 2012; Accepted 4 June 2012

Academic Editor: Felipe Dal-Pizzol

Copyright (C 2012 Edilia Tapia et al. This is an open access article distributed under the Creative Commons Attribution License, which permits unrestricted use, distribution, and reproduction in any medium, provided the original work is properly cited.

\begin{abstract}
Renal injury resulting from renal ablation induced by 5/6 nephrectomy (5/6NX) is associated with oxidant stress, glomerular hypertension, hyperfiltration, and impaired Nrf2-Keap1 pathway. The purpose of this work was to know if the bifunctional antioxidant curcumin may induce nuclear translocation of Nrf2 and prevents 5/6NX-induced oxidant stress, renal injury, decrease in antioxidant enzymes, and glomerular hypertension and hyperfiltration. Four groups of rats were studied: (1) control, (2) 5/6NX, (3) $5 / 6 \mathrm{NX}+\mathrm{CUR}$, and (4) CUR $(n=8-10)$. Curcumin was given by gavage to NX5/6+CUR and CUR groups $(60 \mathrm{mg} / \mathrm{kg} / \mathrm{day})$ starting seven days before surgery. Rats were studied 30 days after NX5/6 or sham surgery. Curcumin attenuated 5/6NXinduced proteinuria, systemic and glomerular hypertension, hyperfiltration, glomerular sclerosis, interstitial fibrosis, interstitial inflammation, and increase in plasma creatinine and blood urea nitrogen. This protective effect was associated with enhanced nuclear translocation of Nrf2 and with prevention of 5/6NX-induced oxidant stress and decrease in the activity of antioxidant enzymes. It is concluded that the protective effect of curcumin against 5/6NX-induced glomerular and systemic hypertension, hyperfiltration, renal dysfunction, and renal injury was associated with the nuclear translocation of Nrf2 and the prevention of both oxidant stress and the decrease of antioxidant enzymes.
\end{abstract}

\section{Introduction}

Curcumin is the major active component of turmeric, a yellow compound isolated from the plant Curcuma longa and has been used for centuries in traditional medicines [1]. Extensive research over the past 30 years has indicated that this molecule has therapeutic potential against a wide range of diseases, such as cancer, lung diseases, renal diseases, neurological diseases, liver diseases, metabolic diseases, cardiovascular diseases, and various other inflammatory diseases [1-3]. Numerous lines of evidence indicate that curcumin is highly pleiotropic with anti-inflammatory [46], hypoglycemic [7], antioxidant [8-11], wound healing [12] and antimicrobial activities [13]. Curcumin exerts both direct and indirect antioxidant effects by scavenging reactive oxygen species (ROS) $[14,15]$ and inducing the expression of cytoprotective proteins in an Nrf2-dependent way [16], respectively. It is considered a bifunctional antioxidant [17]. The nuclear-factor-erythroid-2-related factor 2 (Nrf2), is a cap " $n$ " collar (CNC) basic region leucine zipper transcription protein and a ubiquitous master transcription factor which induces cytoprotective proteins trough binding 
to antioxidant response elements (AREs) $[18,19]$. Nrf2 is held in the cytoplasm, under basal conditions, as an inactive complex bound to a repressor molecule known as Kelchlike ECH-associated protein 1 (Keap1), which facilitates its ubiquitination. Keap1 is the redox-sensitive protein that on stimulus allows the activation of Nrf2. Nrf2 can be activated by diverse stimuli including oxidants, antioxidants, and chemopreventive agents. Keap1 contains several reactive cysteine residues that serve as sensors of intracellular redox state [20]. Oxidative or covalent modification of thiols in some of these cysteine residues results in dissociation of Nrf2 from Keap 1 and its translocation to the nucleus. Previous work of our group have shown that curcumin indeed was able to induce in vivo translocation of Nrf2 to the nucleus which was associated with the renoprotection of this antioxidant against potassium-dichromate-induced nephrotoxicity in rats [8]. On the other hand, it has been shown that curcumin exerts protective effects against renal damage and inflammation induced by $5 / 6$ nephrectomy $(5 / 6 \mathrm{NX})$ in rats $[4,21]$, a widely used model to study the progression of renal disease $[22,23]$. This experimental model is characterized by proteinuria, hypertension, glomerular sclerosis, arteriolopathy, renal inflammation and fibrosis, and alterations in renal hemodynamics including glomerular hypertension and hyperfiltration [22-25]. It has been shown that glomerular hypertension and hyperfiltration are involved in the progression of renal damage in 5/6NX rats [24-26]. Furthermore, it has been shown that oxidant stress, increase in nicotinamide adenine dinucleotide phosphate (NADPH) oxidase and alterations in antioxidant enzymes are involved in the pathogenesis of 5/6NX [27, 28]. More recently, Kim and Vaziri [28] have shown that the impaired Nrf2-Keap1 pathway contributes to oxidative stress and inflammation in 5/6NX rats. They showed that remnant kidney tissue Nrf2 activity (nuclear translocation) was reduced, whereas the Nrf2 repressor Keap1 was upregulated [28]. At present it is unknown if curcumin is able to ameliorate 5/6NXinduced glomerular hypertension and hyperfiltration and to modulate nuclear translocation of Nrf2 in this model. Based on the above information, the hypothesis was made that curcumin may enhance nuclear Nrf2 translocation which may decrease 5/6NX-induced oxidant stress, alterations in renal hemodynamics, and renal injury. The present study was designed to investigate if curcumin administration results in attenuation of renal hemodynamic alterations in rats with $5 / 6 \mathrm{NX}$ and if this may be associated to Nrf2 nuclear translocation and attenuation of both oxidant stress and decrease in antioxidant enzymes. Furthermore, it was explored if this experimental model is associated with mitochondrial alterations that may be involved in the pathophysiology of the disease as has been shown in other models of renal damage [8, 29-33].

\section{Method}

2.1. Chemicals. Curcumin, nitroblue tetrazolium (NBT), tetramethoxypropane, glutathione reductase, reduced glutathione (GSH), oxidized glutathione (GSSG), 1-chloro2, 4-dinitrobenzene (CDNB), ethylenediaminetetraacetic acid (EDTA), Tris-HCl, 1-methyl-2-phenylindole, xanthine, xanthine oxidase, NADPH, aprotinin, leupeptin, pepstatin, $\mathrm{N}$-[2-hydroxyethyl]piperazine- $\mathrm{N}^{\prime}$-[2-ethanesulfonic acid] (HEPES), butylated hydroxytoluene, bovine serum albumin, dimedone (5, 5-dimethyl-1, 3-cyclohexanedione), boric acid, Brij solution 30\% (w/v), O-phthalaldehyde, 2mercaptoethanol, ethanol, adenosine diphosphate (ADP), potassium succinate, rotenone, sodium glutamate, sodium malate, carbonyl cyanide m-chlorophenyl hydrazone (CCCP), Sudan Black, hematoxylin, eosin, and periodic acid Schiff were purchased from Sigma-Aldrich (St. Louis, MO, USA). Hydrogen peroxide $\left(\mathrm{H}_{2} \mathrm{O}_{2}\right)$ and trichloroacetic acid (TCA) were purchased from J. T. Baker (Xalostoc, Edo. Mex, México). Sodium pentobarbital was from Holland of México (Mexico City). Rabbit IgG anti-Nrf2 polyclonal antibody (Cat \#sc722) was purchased from Santa Cruz Biotechnology (Santa Cruz, CA, USA). Inutest (25\% polyfructosan solution) was from Fresenius Kabi Austria $\mathrm{GmbH}$ (Linz, Austria). All other reagents and chemicals used were of the highest grade of purity commercially available.

2.2. Experimental Design. Male Wistar rats with an initial body weight of 280-300 g were used. All animal procedures were performed in accordance to the Mexican Federal Regulation for animal experimentation and care (NOM062-ZOO-2001) and for the disposal of biological residues (NOM-087-ECOL-1995) and were approved by Bioethics and Investigation Committees of Instituto Nacional de Cardiología Ignacio Chávez (Approval No. 12-767). Under anesthesia with sodium pentobarbital, $60 \mathrm{mg} / \mathrm{kg}$ intraperitoneally, renal ablation was performed by removal of the right kidney and selective infarction of approximately two thirds of the left kidney by ligation of two or three branches of the renal artery. Sham operation consisted of ventral laparotomy and manipulation of the kidneys and renal pedicle without destruction of renal tissue [22]. Four groups of rats were studied and all animals were sacrificed 30 days after 5/6NX or laparotomy: (1) control rats $(n=9)$, treated daily via oral gavage with carboxymethylcellulose $0.05 \% 7$ days before and 30 days after laparotomy; (2) 5/6NX-treated rats (5/6NX group, $n=9)$; (3) 5/6NX + curcumin (5/6NX+CUR group, $n=8$ ); (4) curcumin-treated rats (CUR group, $n=10$ ). Curcumin was dissolved in carboxymethylcellulose $0.05 \%$ and was given daily at a dose of $60 \mathrm{mg} / \mathrm{kg} /$ day via oral gavage for 7 days before and 30 days after 5/6NX (5/6NX+CUR group) or sham operation (CUR group). The dose of curcumin used $(60 \mathrm{mg} / \mathrm{kg} /$ day $)$ was chosen based on previous experiments in which lower doses of 15 and $30 \mathrm{mg} / \mathrm{kg} /$ day were ineffective to ameliorate proteinuria and hypertension in our rats. In addition, Kuhad et al. [34] observed the higher protection against cisplatin-induced nephrotoxicity with $60 \mathrm{mg}$ of curcumin/kg/day. Systolic blood pressure (SBP) was measured in conscious restrained rats by tail-cuff plethysmography (XBP-1000 Kent Scientific, Connecticut, USA). Rats were preconditioned twice before SBP was measured at basal period, and every two weeks for the rest of the study as described in earlier studies [22]. In addition to tail-cuff plethysmography, blood pressure 
was also determined by direct intra-arterial measurement through the experiment by a catheter placed in the femoral artery during the micropuncture experiments (see later). Twenty-four-hour urine collections were obtained placing the rats in metabolic cages at baseline and at every 2 weeks during the study, before the micropuncture experiments. Proteinuria and systolic blood pressures were measured in basal conditions and on days 15 and 30 and plasma creatinine and blood urea nitrogen (BUN) were measured on day 30 .

\subsection{Micropuncture Studies to Evaluate Renal Hemodynam-} ics. Micropuncture studies were performed 30 days after the surgical procedure $(5 / 6 \mathrm{NX}$ or sham) under sodium pentobarbital anesthesia $(30 \mathrm{mg} / \mathrm{kg}$ body weight intraperitoneally) with supplementary doses as required. Micropuncture methodology has been previously described [22] briefly; the rats were placed on a temperature-regulated table, at $37^{\circ} \mathrm{C}$. Polyethylene tubing was used to catheterize the trachea jugular veins, femoral arteries, and the left ureter. The left kidney was exposed, through a lumbar incision, placed in a Lucite holder, and sealed, covering the kidney surface with $0.9 \%$ saline solution. One femoral artery catheter was used for blood sampling and the other for monitoring mean arterial pressure (MAP) with a pressure transducer (Model p23 Db, Gould, Puerto Rico, USA) and recorded on a polygraph (Grass Instruments, Quincy, MA, USA). During the surgery, rats received an albumin (6\%) infusion ( $1 \%$ of body weight), through a jugular catheter. Immediately after a bolus injection of $100 \mathrm{mg}$ of polyfructosan, an infusion of 5\% polyfructosan in Ringer solution was started at a rate of $2.2 \mathrm{~mL} / \mathrm{h}$. Sixty minutes were allowed for equilibration before the studies were done. Sampling blood was simultaneously replaced by an equal volume obtained from a normal donor rat. At the end of the experiment the kidneys were removed and weighed. Samples of proximal tubule fluid were obtained from seven different nephrons after inserting an oil block with a micropipette for determination of flow rate and polyfructosan concentration to calculate single-nephron glomerular filtration rate (SNGFR). Polyfructosan was measured in plasma and urine samples to calculate whole-kidney glomerular filtration rate (GFR). Using a continuous-recording servo-null micropipette transducer (Servo Nulling Pressure System, Instrumentation for Physiology and Medicine, Inc., California, CA, USA), intratubular hydrostatic pressure (FF), was measured in additional proximal tubules under freeflow conditions and after stopping tubular flow with an oil block (stop-flow pressure); hydrostatic pressure was also measured in peritubular capillaries. Colloid osmotic pressure $(\pi)$ in glomerular capillaries was estimated from the protein concentration in blood taken from the femoral artery $(\mathrm{Ca})$ and in blood obtained by puncturing surface efferent arterioles (Ce) [35]. The following variables were measured: MAP, stop-flow pressure (SFP), transcapillary hydraulic pressure $(\Delta \mathrm{P})$, hematocrit $(\mathrm{Hct})$, free flow pressure (FFP), capillary pressure (Pc), and afferent (CA) and efferent (CE) protein concentration.
2.4. Analytical Procedures. Urea and creatinine were measured with an autoanalyzer (I lab 300 Plus Instrumentation Laboratory, Bedford, MA, USA). Proteinuria was measured by a turbidimetric method at $420 \mathrm{~nm}$ using $12.5 \%$ TCA and data were expressed as $\mathrm{mg} / 24 \mathrm{~h}$ [36]. Polyfructosan concentrations in plasma and urine were determined by the anthrone method [37]. The volume of fluid collected from individual proximal tubules was estimated from the length of the fluid column in a constant-bore capillary tube of known internal diameter. The concentration of polyfructosan in the tubular fluid was measured in triplicate by a microfluorometric method [38]. Protein concentrations were determined in efferent samples and femoral arterial blood plasma using a fluorometric method[39]. GFR, SNGFR, glomerular capillary pressure $\left(\mathrm{P}_{\mathrm{GC}}\right)$, single-nephron plasma flow $(\mathrm{Qa})$, single-nephron filtration fraction (SNFF), afferent (AR) an efferent (ER) resistances, afferent $(\pi \mathrm{A})$ and efferent $(\pi \mathrm{E})$ oncotic pressure, and ultrafiltration coefficient (Kf) were calculated according to Baylis et al. [35].

2.5. Histological Analysis. Paraffin-embedded sections stained with trichrome and periodic acid-Schiff reagent (PAS) were examined in a blinded fashion. Tubulointerstitial fibrosis was evaluated in Masson's trichrome sections. Thirty nonoverlapping fields of cortex $(640 \times 477 \mathrm{mM}$ at $10 \mathrm{X})$ per biopsy were analyzed by light microscopy (Olympus BX51, Olympus American, New York, USA) and captured with a digital video camera (Evolution VF, Media Cybernetics, Madison, USA). Positive blue-color areas (excluding glomeruli and vessels) were analyzed using Image-Pro-Plus 7.0 (Media Cybernetics). The extension of positive areas (30 microscopic fields per biopsy) was expressed as a fraction of the total tubulointerstitial area examined. Tubulointerstitial cellular infiltration was studied in PAS sections. The number of cells by field was quantified and expressed as positive cells per field. Glomerulosclerosis was evaluated in Masson's trichrome stained sections. The degree of sclerosis was scored as follows: in each biopsy, the number of glomeruli with segmental, mesangial, and global sclerosis, as well as normal glomerular tufts, was assessed. Sclerosis was defined as a peripheral segmental or global increase in mesangial matrix with obliteration of capillary loops, far from the hilus. The resulting index in each animal was expressed as the percent of sclerosed glomeruli [24].

2.6. Nrf2 Immunohistochemistry. Sections $(2 \mu \mathrm{m})$ were deparaffinized and rehydrated through submersion in graded alcohols (xylene 1:1 xylene-alcohol, alcohol, and 70\% alcohol for $10 \mathrm{~min}$ each, and finally rinsed in distilled water). Antigen retrieval was performed with $10 \mathrm{mM}$ citrate buffer $\mathrm{pH}$ 6, for $5 \mathrm{~min}$ in a microwave oven. Samples were treated with $\mathrm{H}_{2} \mathrm{O}_{2}$ (3\%) to quench endogenous peroxidase. Sections were incubated at $4{ }^{\circ} \mathrm{C}$ overnight with a dilution $1: 100$ of anti-Nrf2 antibody. To detect the specific binding of the primary antibody, an immunocytochemical staining kit was used in which tissues were incubated sequentially with blocking serum, a specific secondary antibody and streptavidin/peroxidase complex. Finally, diaminobenzidine 
was used as chromogen. Sections were counterstained with haematoxylin. The percentage of cells with immunostained nuclei was determined and results were expressed as positive nuclei/field.

2.7. Lipid Peroxidation. Lipid peroxidation was assessed by measuring malondialdehyde (MDA), and 4-hydroxy-2nonenal (4-HNE) in the kidney tissue using a standard curve of tetramethoxypropane. A solution of 1-methyl-2phenylindole in a mixture of acetonitrile/methanol $(3: 1)$ was added to the renal homogenates and the reaction was started by adding 37\% $\mathrm{HCl}$. Optical density was measured at $586 \mathrm{~nm}$ after $1 \mathrm{~h}$ of incubation at $45^{\circ} \mathrm{C}$ as previously described [8]. Data were expressed as nmol MDA and 4$\mathrm{HNE} / \mathrm{mg}$ protein.

2.8. Activity of Antioxidant Enzymes. Catalase (CAT) activity was assayed by a method based on the disappearance of 30 $\mathrm{mM} \mathrm{H}_{2} \mathrm{O}_{2}$ at $240 \mathrm{~nm}$ [8] and the data were expressed as $\mathrm{k} / \mathrm{mg}$ protein. GR activity was assayed using GSSG as substrate and measuring the disappearance of NADPH at $340 \mathrm{~nm}$ [8]. One unit of GR was defined as the amount of enzyme that oxidizes $1 \mu \mathrm{mol}$ of $\mathrm{NADPH} / \mathrm{min}$. Data were expressed as $\mathrm{U} / \mathrm{mg}$ protein. Glutathione peroxidase (GPx) activity was measured at $340 \mathrm{~nm}$ using GR and NADPH in a coupled reaction [8]. One unit of GPx was defined as the amount of enzyme that oxidizes $1 \mu \mathrm{mol}$ of $\mathrm{NADPH} / \mathrm{min}$. Data were expressed as U/mg protein. Glutathione-S-transferase (GST) activity was assayed in a mixture containing GSH and CDNB as previously described [8]. One unit of GST was defined as the amount of enzyme that conjugates $1 \mu \mathrm{mol}$ of CDNB with GSH per minute [8]. Data were expressed as U/mg protein. Total superoxide dismutase (SOD) activity in renal homogenates was assayed spectrophotometrically at $560 \mathrm{~nm}$ by a previously reported method using NBT as the indicator reagent [8]. The amount of protein that inhibited NBT reduction to $50 \%$ of maximum was defined as one unit of SOD activity. Results were expressed as U/mg protein.

2.9. Isolation of Renal Mitochondria. Mitochondria were isolated from separate groups of rats prepared exclusively for this purpose. Kidneys were removed from rats, washed, cleaned of fatty and conjunctive tissue, and placed in cold isolation buffer containing $250 \mathrm{mM}$ sucrose, $10 \mathrm{mM}$ Tris$\mathrm{HCl}, 1 \mathrm{mM}$ EDTA, and $\mathrm{pH}$ 7.3. Kidneys were minced in isolation buffer before being homogenized. Mitochondria were obtained by differential centrifugation as previously described [40].

2.10. Mitochondrial Oxygen Consumption. Mitochondrial oxygen consumption was measured using a Clark-type oxygen electrode (Yellow Springs Instruments, Yellow Spring, $\mathrm{OH}$, USA). The experiments were carried out in $1.5 \mathrm{~mL}$ of basic medium containing $125 \mathrm{mM} \mathrm{KCl,} 10 \mathrm{mM}$ HEPES, and $3 \mathrm{mM}$ inorganic phosphate $(\mathrm{Pi}), \mathrm{pH}$ 7.3. State 4 respiration was evaluated in the presence of $10 \mathrm{mM}$ succinate plus $1 \mu \mathrm{g} / \mathrm{mL}$ rotenone, or with $10 \mathrm{mM}$ sodium glutamate and $10 \mathrm{mM}$ sodium malate. State 3 respiration was stimulated by the addition of $200 \mu \mathrm{M}$ ADP. Respiratory rates are expressed as ng-atoms oxygen $/ \mathrm{min} / \mathrm{mg}$ protein $(\mathrm{ngAO} / \mathrm{min} / \mathrm{mg})$. Respiratory control index (RC) was calculated as the ratio state $3 /$ state 4 . Uncoupled respiration was measured by adding $1 \mu \mathrm{M}$ CCCP; phosphorylation efficiency (ADP/O ratio) was calculated from the added amount of ADP and total amount of oxygen consumed during state 3 [8].

2.11. Statistical Analysis. Data are presented as mean \pm standard error of the mean (SEM). Differences between groups were evaluated by two-way analysis of variance (ANOVA) followed by multiple comparisons according to Bonferroni using a commercially available statistical package (GraphPad Prism 4.0, California, USA). Two-tailed $P<0.05$ was considered significant.

\section{Results}

3.1. Plasma Creatinine, BUN, Proteinuria, and Systolic Blood Pressure. Rats in all the experimental groups had comparable body weight, blood pressure, and urinary protein excretion in the baseline studies and had comparable body weights at the end of the experiment (data not shown). At the end of the study, it was found that curcumin attenuates proteinuria and the increase in plasma creatinine, blood urea nitrogen, and systolic blood pressure (Figure 1). BUN decreased from $100 \mathrm{mg} / \mathrm{dL}$ in the $5 / 6 \mathrm{NX}$ group to $30 \mathrm{mg} / \mathrm{dL}$ in the $5 / 6 \mathrm{NX}+\mathrm{CUR}$ group. Plasma creatinine decreased from $1.7 \mathrm{mg} / \mathrm{dL}$ in the $5 / 6 \mathrm{NX}$ group to $1.0 \mathrm{mg} / \mathrm{dL}$ in the $5 / 6 \mathrm{NX}+\mathrm{CUR}$ group. Rats with renal ablation developed severe systemic hypertension. Subtotal renal ablation was followed by the progressive increase in proteinuria. As shown in Figure 1(c), proteinuria in the 5/6NX+CUR group was reduced by approximately two-thirds $(P<0.05)$ and remained at essentially steady levels 30 days after 5/6NX. Systolic blood pressure rose from $120 \pm 3$ at day 0 to $178 \pm 6 \mathrm{~mm} \mathrm{Hg}$ at 30 days. Treatment with curcumin was associated with a less-pronounced increment in blood pressure (152 $\pm 4 \mathrm{~mm} \mathrm{Hg}$, Figure 1). In addition the increase in kidney weight (KW) in 5/6NX rats was not significant (Table 1) but curcumin decreased significantly KW about $25 \%$ in the $5 / 6 \mathrm{Nx}+\mathrm{CUR}$ group (Table 1 ).

3.2. Micropuncture Studies. Findings in the micropuncture studies 30 days after $5 / 6 \mathrm{NX}$ are shown in Figure 2. It was found that the increase in (a) MAP, (b) SNGFR, (c) Qa, (d) $\mathrm{P}_{\mathrm{GC}}$, (e) SFP, and (f) $\Delta \mathrm{P}$ observed in $5 / 6 \mathrm{NX}$ rats was ameliorated by curcumin $(5 / 6 \mathrm{NX}+\mathrm{CUR}$ group). Curcumin prevented glomerular hypertension (the increase in $\mathrm{P}_{\mathrm{GC}}$ ) and hyperfiltration (the increase in SNGFR). In addition it was found that the decrease in (g) AR, (h) ER, and (i) GFR observed in 5/6NX rats was ameliorated by curcumin (5/6NX+CUR group). The most relevant changes observed in the 5/6NX+CUR group were the normalization of $\mathrm{P}_{\mathrm{GC}}$ and $\mathrm{SNGFR}$ resulting from a significant increase in the preglomerular tone evidenced by the rise in AR. No significant differences were observed in Hct, SNFF, FFP, Pc, $\mathrm{Kf}, \mathrm{CA}, \pi \mathrm{A}, \mathrm{CE}$, and $\pi \mathrm{E}$ (Table 1 ). 


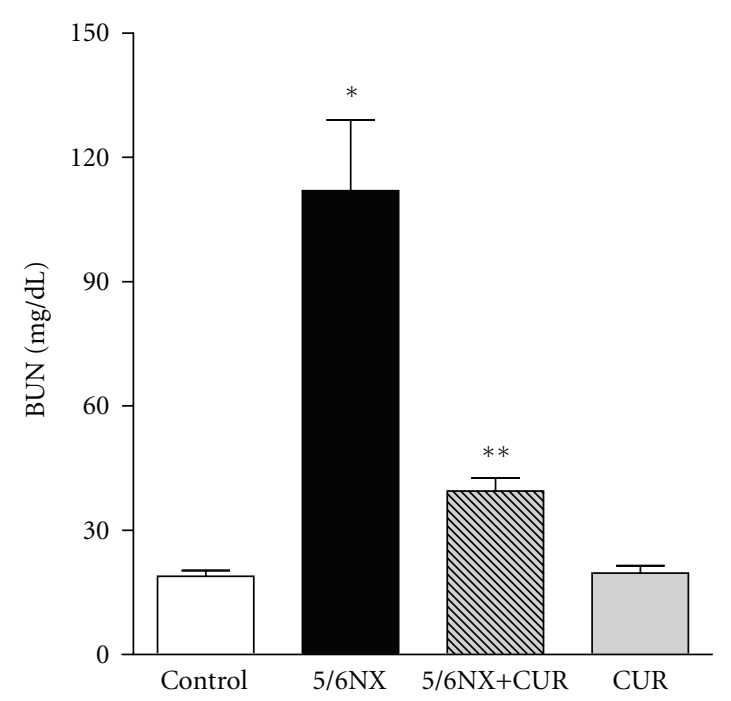

(a)

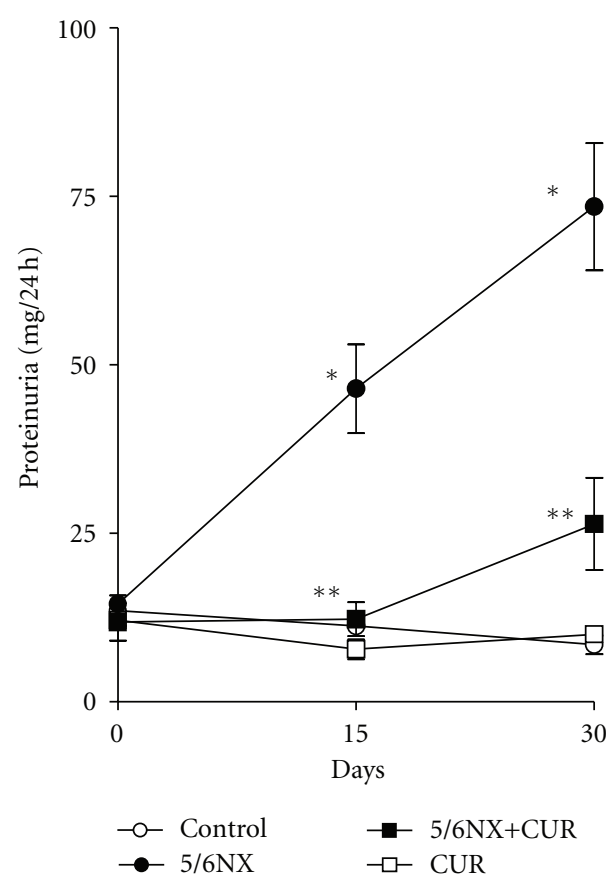

(c)

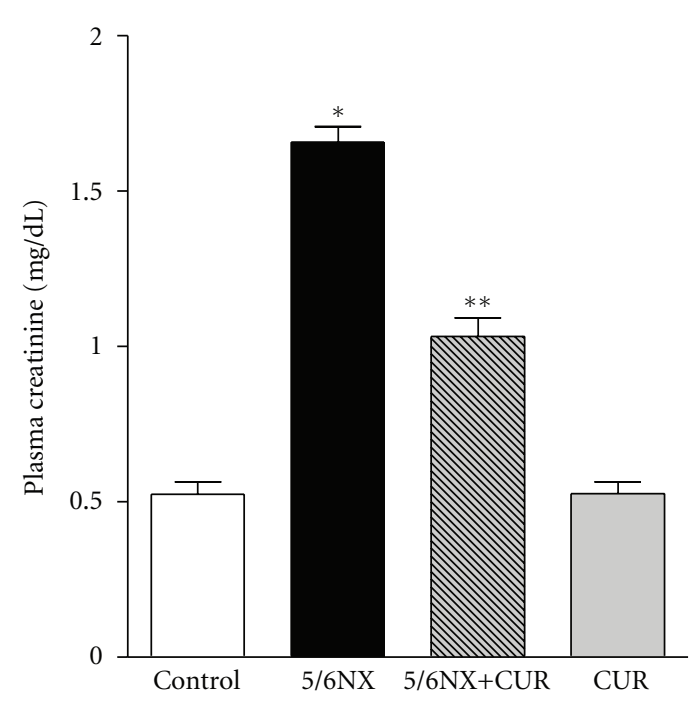

(b)

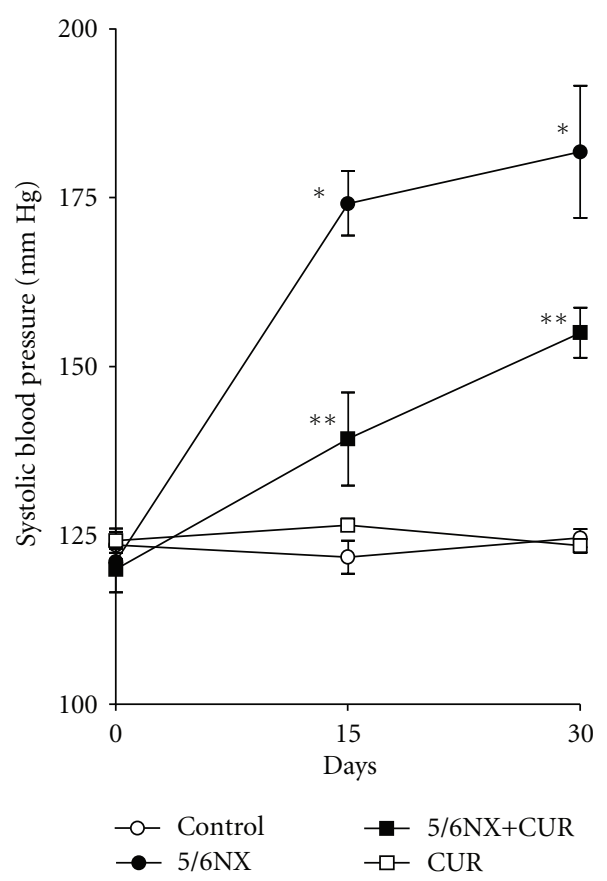

(d)

FIgURE 1: Curcumin $(60 \mathrm{mg} / \mathrm{kg} / \mathrm{day})$ ameliorated 5/6NX-induced increase in (a) blood urea nitrogen (BUN), (b) plasma creatinine, (c) proteinuria, and (d) systolic blood pressure. BUN and plasma creatinine were measured at the end of the study (day 30$)$. Data are mean \pm SEM of $8-10$ rats. ${ }^{*} P<0.05$ versus control, ${ }^{* *} P<0.05$ versus $5 / 6 \mathrm{NX}$.

3.3. Histological Analysis. Figure 3 shows that $5 / 6 \mathrm{NX}$ rats developed glomerular sclerosis. Representative images are shown in the upper panel and quantitative data are shown in the lower panel. Curcumin treatment ameliorated significantly glomerular sclerosis from $25 \%$ in the $5 / 6 \mathrm{NX}$ groups to $12 \%$ in the $5 / 6 \mathrm{NX}+\mathrm{CUR}$ group $(P<0.05)$. No sclerosis was observed in control and CUR groups (Figure 3 ).

Figure 4 shows that 5/6NX rats developed interstitial fibrosis. Representative images are shown in the upper panel and quantitative data are shown in the lower panel. Curcumin treatment ameliorated significantly interstitial fibrosis from $9 \%$ in the $5 / 6 \mathrm{NX}$ group to $4 \%$ in the $5 / 6 \mathrm{NX}+\mathrm{CUR}$ group $(P<0.05)$. These values were lower than $1 \%$ in control and CUR groups (Figure 4).

Figure 5 shows that 5/6NX rats developed interstitial inflammation. Representative images are shown in the upper panel and quantitative data are shown in the lower panel. Curcumin treatment ameliorated significantly interstitial inflammation from 50 cells/field in the $5 / 6 \mathrm{NX}$ groups to 20 cells/field in the $5 / 6 \mathrm{NX}+\mathrm{CUR}$ group $(P<0.05)$. These values were lower than 15 cells/filed in control and CUR groups (Figure 5). 
TABLE 1: Glomerular hemodynamic findings 30 days after 5/6 nephrectomy.

\begin{tabular}{lcccc}
\hline & Control & $5 / 6 \mathrm{NX}$ & $5 / 6 \mathrm{NX}+\mathrm{CUR}$ & CUR \\
\hline KW $(\mathrm{g})$ & $1.58 \pm 0.05$ & $1.72 \pm 0.12$ & $1.29 \pm 0.05^{* *}$ & $1.66 \pm 0.08$ \\
$\mathrm{Hct}(\%)$ & $0.48 \pm 0.01$ & $0.47 \pm 0.01$ & $0.45 \pm 0.01$ & $0.49 \pm 0.01$ \\
SNFF $(\%)$ & $0.30 \pm 0.02$ & $0.30 \pm 0.02$ & $0.29 \pm 0.02$ & $0.26 \pm 0.01$ \\
FFP (mm Hg) & $11.54 \pm 0.93$ & $11.02 \pm 0.47$ & $10.24 \pm 1.49$ & $11.07 \pm 0.55$ \\
Pc (mm Hg) & $11.68 \pm 0.62$ & $10.57 \pm 0.57$ & $11.09 \pm 1.06$ & $12.00 \pm 1.10$ \\
Kf $(\mathrm{nL} \cdot \mathrm{sec} \cdot \mathrm{mm} \mathrm{Hg})$ & $0.0338 \pm 0.0016$ & $0.0296 \pm 0.0008$ & $0.0375 \pm 0.0004$ & $0.0318 \pm 0.0007$ \\
$\mathrm{CA}(\mathrm{g} / 100 \mathrm{~mL})$ & $5.00 \pm 0.15$ & $5.22 \pm 0.17$ & $5.07 \pm 0.32$ & $5.66 \pm 0.23$ \\
$\pi \mathrm{A}(\mathrm{mm} \mathrm{Hg})$ & $15.75 \pm 0.79$ & $16.87 \pm 0.13$ & $16.31 \pm 1.57$ & $19.00 \pm 1.14$ \\
$\mathrm{CE}(\mathrm{g} / 100 \mathrm{~mL})$ & $7.12 \pm 0.21$ & $7.42 \pm 0.13$ & $7.12 \pm 0.28$ & $7.59 \pm 0.34$ \\
$\pi \mathrm{E}(\mathrm{mm} \mathrm{Hg})$ & $26.85 \pm 1.23$ & $28.51 \pm 0.76$ & $26.83 \pm 1.66$ & $29.65 \pm 2.06$ \\
\hline
\end{tabular}

CUR: curcumin, 5/6 NX: five-sixths nephrectomy, KW: kidney weigth, Hct: Hematocrit, SNFF: single-nephron filtration fraction, FFP: Free flow pressure, $P_{c}$ : Peritubular capillary pressure, $K_{f}$ : ultrafiltration coefficient, $C_{A}$ : afferent protein concentration, $\pi A$ : afferent oncotic pressure, $C_{E}$ : efferent protein concentration, $\pi E$ : efferent oncotic pressure. Data are mean \pm SEM, $n=7-10$. Two way ANOVA followed by Bonferroni. ${ }^{* *} P<0.05$ versus $5 / 6$ NX.

TABLE 2: Effect of CUR and 5/6NX on mitochondrial oxygen consumption using malate/glutamate or succinate as substrates.

\begin{tabular}{|c|c|c|c|c|}
\hline & Control & $5 / 6 \mathrm{NX}$ & $5 / 6 \mathrm{NX}+\mathrm{CUR}$ & CUR \\
\hline \multicolumn{5}{|c|}{ Malate/glutamate } \\
\hline State $3(\mathrm{ngAO} / \mathrm{min} / \mathrm{mg})$ & $193.9 \pm 19.2$ & $197.3 \pm 7.3$ & $187.9 \pm 12.8$ & $188.8 \pm 17.5$ \\
\hline State $4(\mathrm{ngAO} / \mathrm{min} / \mathrm{mg})$ & $72.6 \pm 8.7$ & $77.7 \pm 6.4$ & $69.7 \pm 4.3$ & $72.9 \pm 7.1$ \\
\hline $\mathrm{RC}$ & $2.8 \pm 0.2$ & $2.5 \pm 0.1$ & $2.7 \pm 0.1$ & $2.6 \pm 0.1$ \\
\hline Uncoupled respiration ( $\mathrm{ngAO} / \mathrm{min} / \mathrm{mg})$ & $233.1 \pm 28.0$ & $238.3 \pm 22.7$ & $225.3 \pm 19.5$ & $247.1 \pm 28.3$ \\
\hline $\mathrm{ADP} / \mathrm{O}$ & $2.2 \pm 0.4$ & $1.8 \pm 0.1$ & $1.9 \pm 0.1$ & $2.1 \pm 0.2$ \\
\hline \multicolumn{5}{|c|}{ Succinate } \\
\hline State $3(\mathrm{ngAO} / \mathrm{min} / \mathrm{mg})$ & $277.1 \pm 31.3$ & $276.1 \pm 20.7$ & $277.1 \pm 14.8$ & $251.1 \pm 24.2$ \\
\hline State $4(\mathrm{ngAO} / \mathrm{min} / \mathrm{mg})$ & $136.4 \pm 14.0$ & $143.0 \pm 13.2$ & $136.1 \pm 5.3$ & $114.1 \pm 0.7$ \\
\hline $\mathrm{RC}$ & $2.0 \pm 0.1$ & $2.0 \pm 0.1$ & $2.0 \pm 0.1$ & $2.2 \pm 0.1$ \\
\hline Uncoupled respiration (ngAO/min/mg) & $414.5 \pm 49.2$ & $340.7 \pm 53.3$ & $399.7 \pm 26.8$ & $425.0 \pm 49.2$ \\
\hline $\mathrm{ADP} / \mathrm{O}$ & $1.3 \pm 0.1$ & $1.2 \pm 0.0$ & $1.2 \pm 0.1$ & $1.4 \pm 0.1$ \\
\hline
\end{tabular}

CUR: curcumin, 5/6NX: five-sixths nephrectomy, RC: respiratory control index, ngAO/min/mg: nanograms atoms oxygen/minute/milligrams protein. ADP/O: phosphorylation efficiency. Data represent mean \pm SEM, $n=7-15$.

Figure 6 shows that curcumin-induced nuclear translocation of Nrf2. Representative images are shown in the upper panel and quantitative data are shown in the lower panel. The increase was higher in the 5/6NX+CUR group (about 6 positive cells/filed) than in the CUR group (about 3 positive cells/field $)(P<0.05)$. These values were lower than 0.5 positive cells/field in control and CUR groups (Figure 6).

3.4. Oxidant Stress and Activity of Antioxidant Enzymes. $5 / 6 \mathrm{NX}$ alterations were associated with increase of about $30 \%$ in lipid peroxidation and decrease of about $10-40 \%$ in the activity of antioxidant enzymes (CAT, GR, GPx, GST, and SOD). It was found that curcumin fully prevented the abovedescribed changes in lipid peroxidation and in antioxidant enzymes (Figure 7).

3.5. Mitochondrial Function. Mitochondrial function was evaluated in all groups in order to explore the possible role of this organelle in the observed renal dysfunction induced by $5 / 6 \mathrm{NX}$. On day 30 , it was found that $5 / 6 \mathrm{NX}$ or curcumin was unable to induce alterations in renal mitochondrial respiration (state 3 , state $4, \mathrm{RC}$, uncoupled respiration, and $\mathrm{ADP} / \mathrm{O}$ ratio using either malate/glutamate or succinate as substrates, Table 2). No significant alterations were found among all the studied groups (Table 2).

\section{Discussion}

It has been shown that oxidant stress plays a major role in the progression of renal damage in patients [41] and in animal models [27, 42-45]. In the 5/6NX model oxidant stress may be explained from an increase in ROS production and a decrease in the expression/activity of antioxidant enzymes [28, 46]. In a recent study, Kim and Vaziri [28] showed that the Nrf2-Keap1/ARE pathway is altered in rats with 5/6NX. The cytoplasmic concentration of Keap1 was increased and the nuclear Nrf2 translocation was decreased. These changes were accompanied by a decrease in the renal content of GSH and of the several enzymes dependent of $\mathrm{Nrf} 2$ as well as an increase in the NADPH oxidase expression [28]. In this context, the use of antioxidant compounds and of inductors of Nrf2 may be useful to attenuate the 


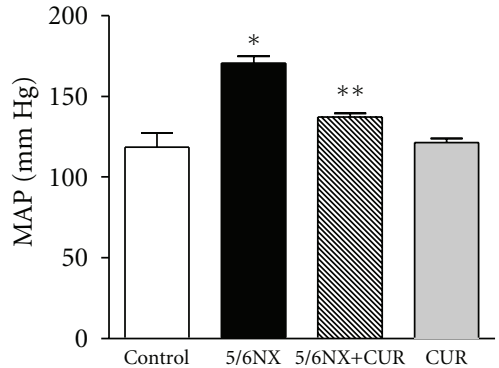

(a)

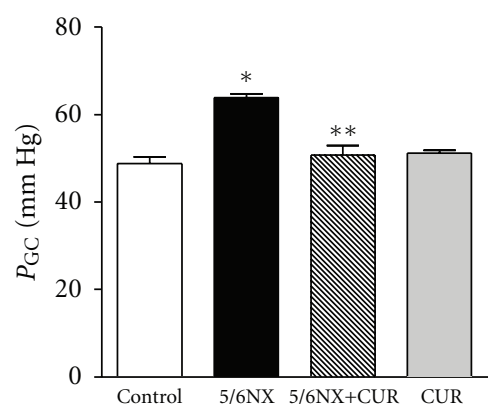

(d)

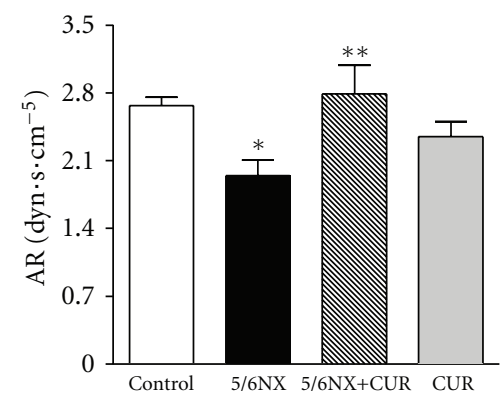

(g)

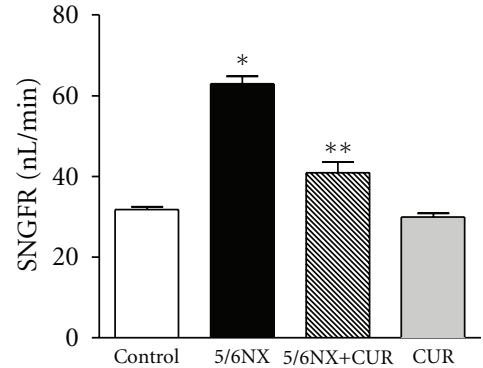

(b)

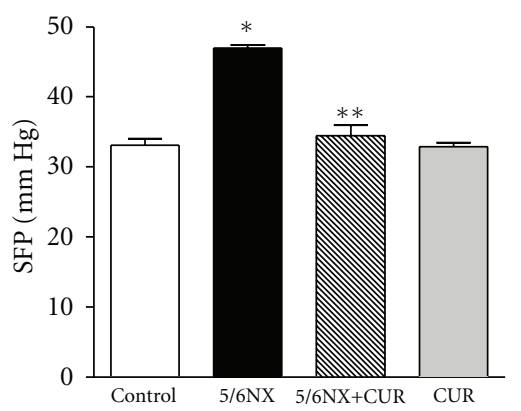

(e)

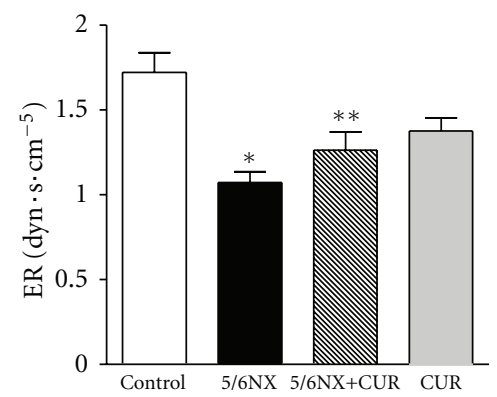

(h)

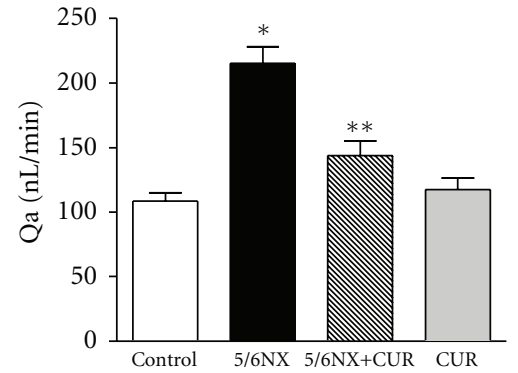

(c)

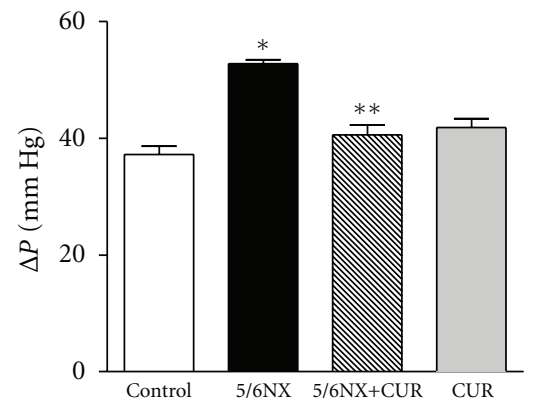

(f)

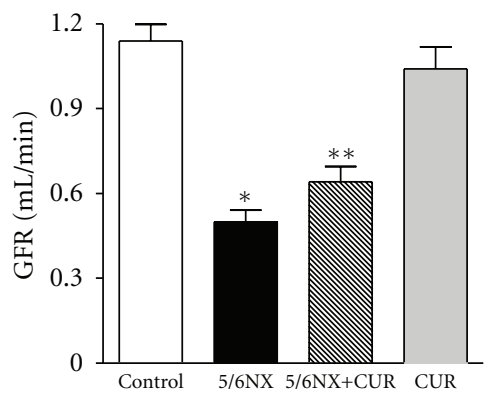

(i)

FIgURE 2: Curcumin $(60 \mathrm{mg} / \mathrm{kg} /$ day) ameliorated 5/6NX-induced alterations in renal hemodynamics at the end of the study (day 30): (a) mean arterial pressure (MAP), (b) single-nephron glomerular filtration rate (SNGFR), (c) single-nephron plasma flow (Qa), (d) glomerular capillary pressure $\left(\mathrm{P}_{\mathrm{GC}}\right),(\mathrm{e})$ stop-flow pressure $(\mathrm{SFP})$ and $(\mathrm{f})$ hydrostatic pressure gradient $(\Delta \mathrm{P}),(\mathrm{g})$ afferent resistance $(\mathrm{AR})$, and $(\mathrm{h})$ efferent resistance (ER), and (i) glomerular filtration rate (GFR) observed in 5/6NX rats was prevented by curcumin (5/6NX+CUR group). Data are mean \pm SEM, $n=8-10$. Two-way ANOVA followed by Bonferroni. ${ }^{*} P<0.05$ versus Control, ${ }^{* *} P<0.05$ versus 5/6NX.

progression of renal damage in rats with 5/6NX. In fact it has been shown in rats with 5/6NX the beneficial effect of the antioxidants such as vitamin E [45], $N$-acetylcysteine [47], melatonin [48], S-allylcysteine [27], and curcumin [4]. The data obtained in the present paper about the protective effect of curcumin on 5/6NX-induced proteinuria, systemic hypertension, histological alterations, and inflammation are consistent with the findings of Ghosh et al. [4, 21]. In addition, here is shown clearly that curcumin significantly ameliorated glomerular hypertension and hyperfiltration, which may limit the extension of renal injury [24-26]. In fact, it has been shown that renal ablation results in hemodynamic changes in the remnant nephrons that engage the participation of proinflammatory and profibrotic mechanisms that amplify nephron loss [49]. The renoprotective effect of curcumin was clearly associated with enhanced translocation of $\mathrm{Nrf2}$, attenuation of oxidant stress, and preservation of the activity of several antioxidant enzymes. Based on the fact that curcumin was given daily along of the study and to the fact that Nrf2 nuclear translocation was enhanced, it is possible that the curcumin-induced decrease of oxidant stress and preservation of the activity of antioxidant enzymes may be secondary to the direct and indirect effect of this bifunctional antioxidant. With this administration protocol is not possible to distinguish between direct and indirect antioxidant effects of curcumin. Interestingly, the protective effect of curcumin against quinolinic acid-induced neurotoxicity is associated to the induction of Nrf2 in striatal tissue [50]. It has been reported that curcumin possesses nephroprotective properties in the experimental models of renal damage induced by cisplatin [34], potassium-dichromate [8], gentamicin [51], sodium fluoride [52], vancomycin [53], cyclosporine [54], acetaminophen [55], ferric nitrilotriacetate [56], and adriamycin [57]. Interestingly, no alterations 
Control

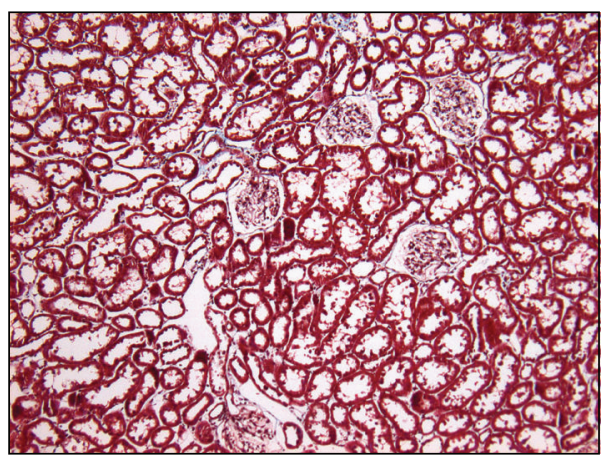

(a)

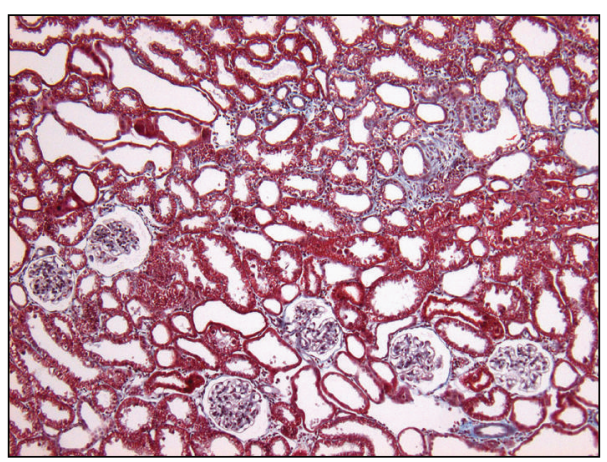

(c)
$5 / 6 \mathrm{NX}$

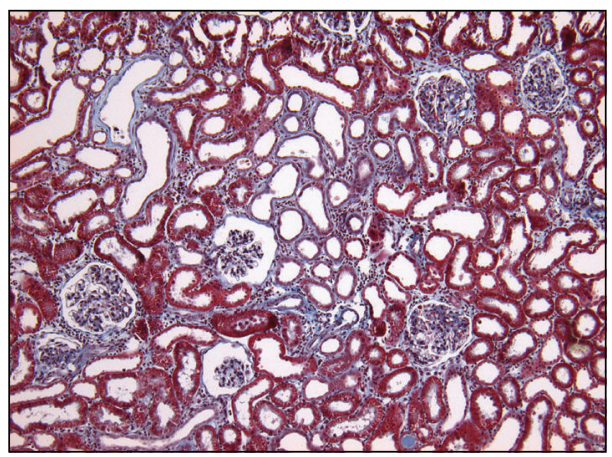

(b)

CUR

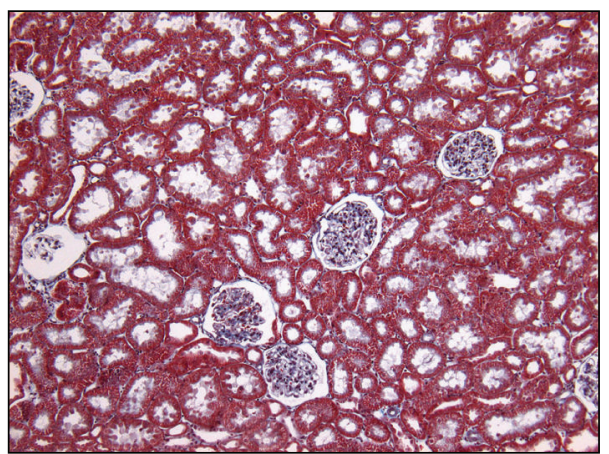

(d)

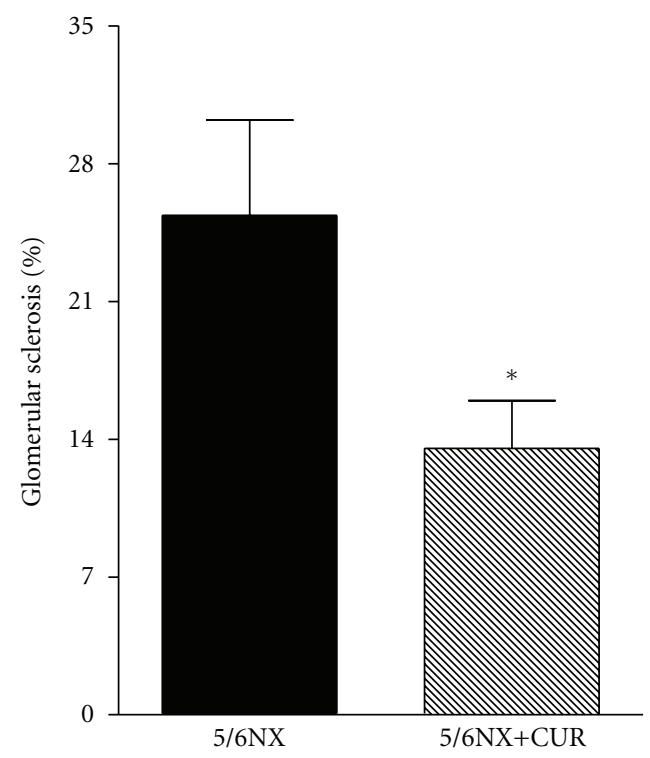

(e)

FIgure 3: Curcumin (60 mg/kg/day) ameliorated 5/6NX-induced glomerular sclerosis at the end of the study (day 30). Upper panels shows representative images of the groups studied. 10X. Lower panel show quantitative data in 5/6NX and 5/6NX+CUR groups. Glomerular sclerosis was absent in control and CUR groups. Data are mean \pm SEM of $8-10$ rats. ${ }^{*} P<0.05$ versus $5 / 6 \mathrm{NX}$.

were found in mitochondrial respiration in 5/6NX rats 30 days after surgery. State 3 , state 4 , RC, uncoupled respiration, and $\mathrm{ADP} / \mathrm{O}$ ratio were unchanged in the four groups of rats studied. To our knowledge, this is the first study of mitochondrial respiration performed in rats with 5/6NX. Alterations in mitochondrial respiration have been found in other models of renal damage induced by potassium dichromate [8], ischemia and reperfusion [29], mercury 


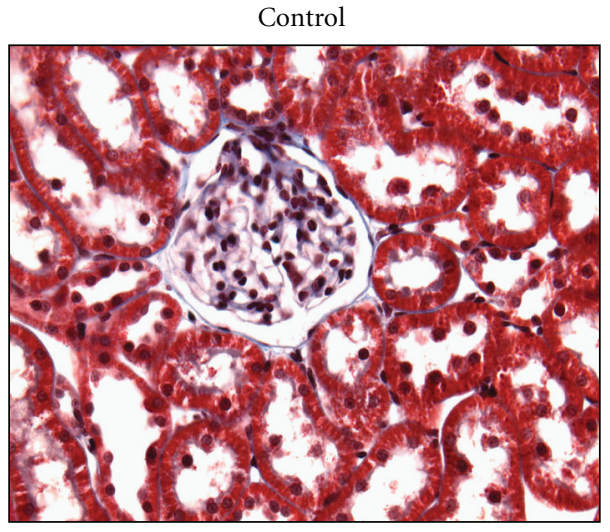

(a)

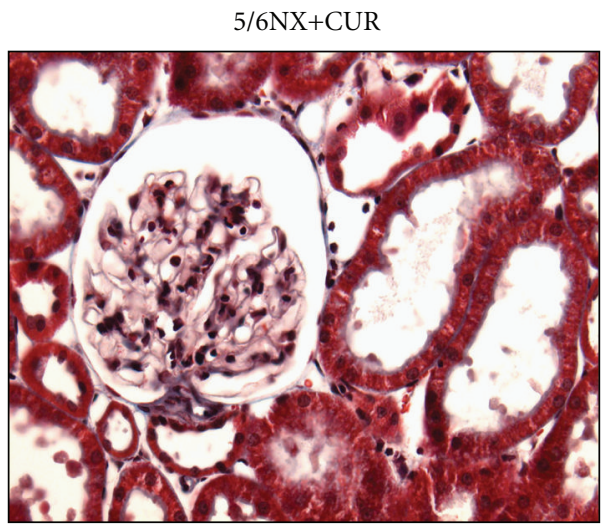

(c)

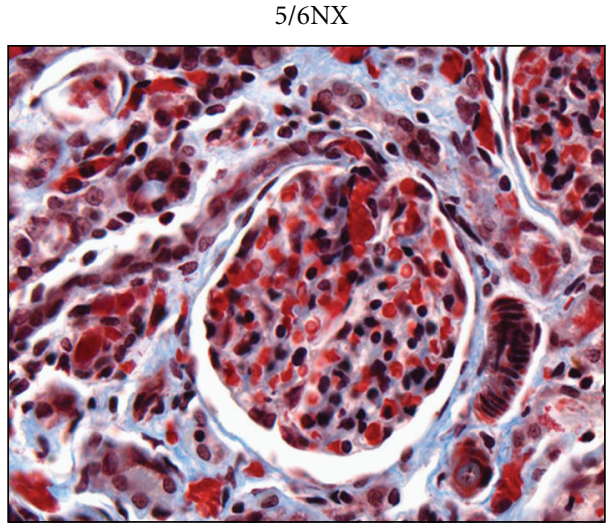

(b)

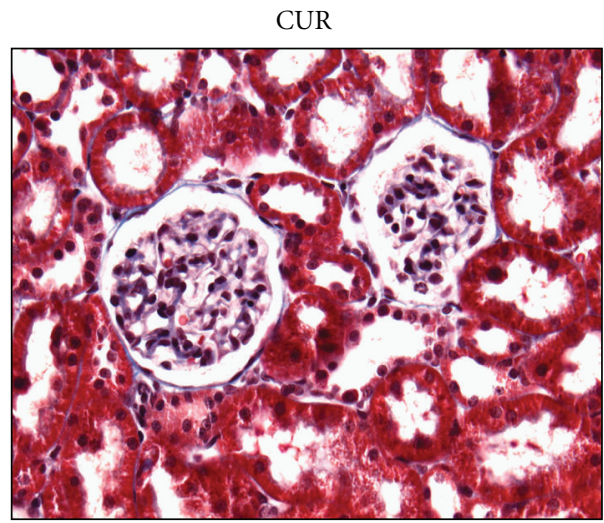

(d)

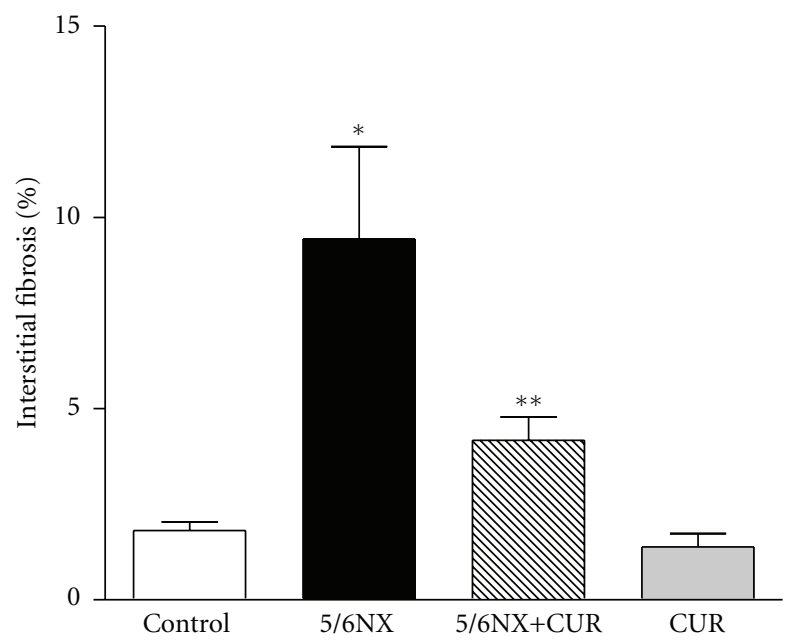

(e)

FIGURE 4: Curcumin (60 mg/kg/day) ameliorated 5/6NX-induced Interstitial fibrosis at the end of the study (day 30). Upper panels shows representative images of the groups studied. $40 \mathrm{X}$. Lower panel show quantitative data. Data are mean \pm SEM of $8-10$ rats. ${ }^{*} P<0.05$ versus control, ${ }^{* *} P<0.05$ versus 5/6NX.

[30], cisplatin [32,33], and gentamicin [31]. It is possible that alterations mitochondrial respiration may be found in this experimental model at longer periods of study (more than 30 days). In conclusion, curcumin treatment results in prevention of the hemodynamic changes in glomerular microcirculation, renal inflammatory injury, and functional deterioration associated with renal mass reduction. The protective effect of curcumin in the remnant kidney was associated with the nuclear translocation of Nrf2 and the prevention of both oxidant stress and the decrease of antioxidant enzymes. It is possible that both direct and indirect antioxidant effects of curcumin may be involved in 


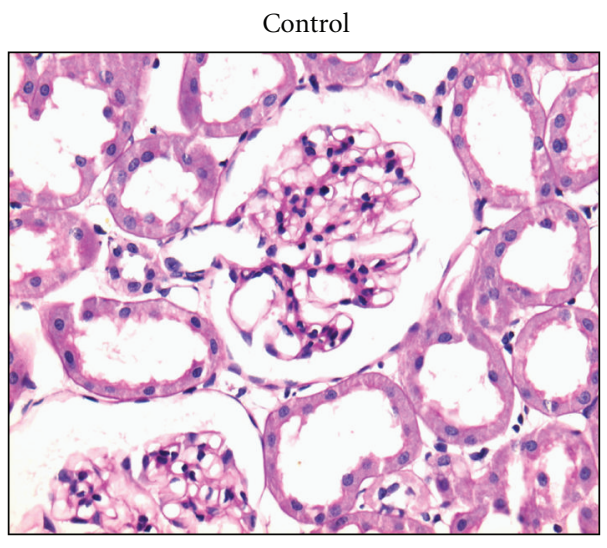

(a)

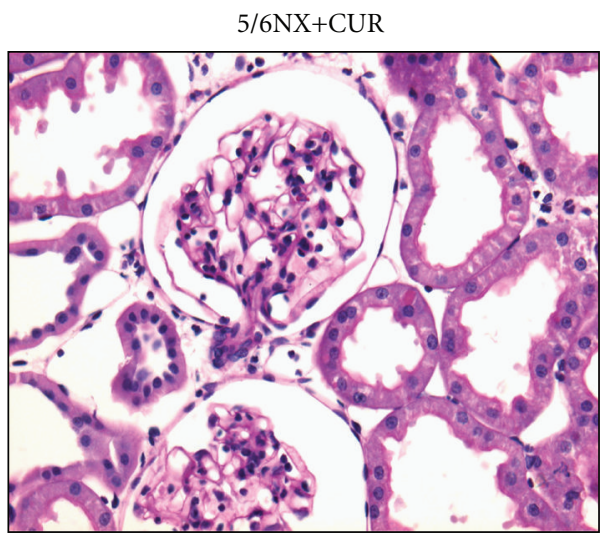

(c)

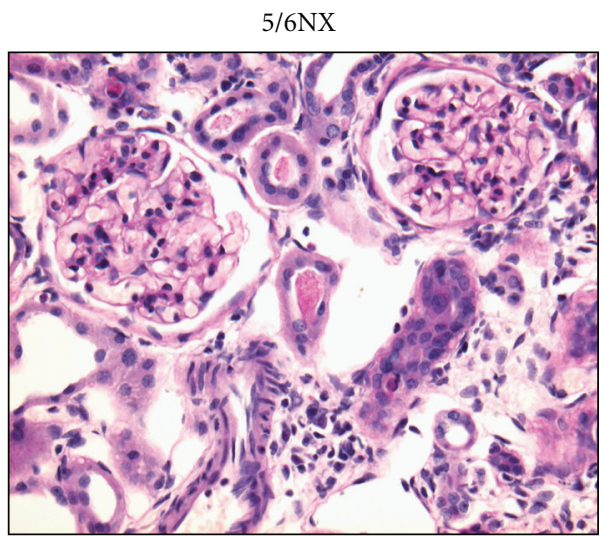

(b)

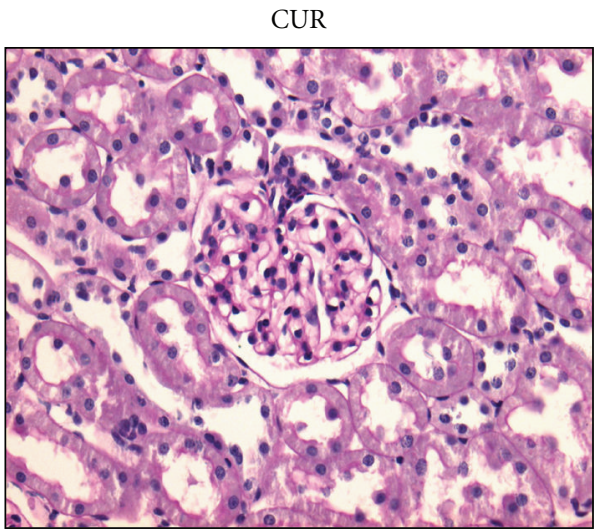

(d)

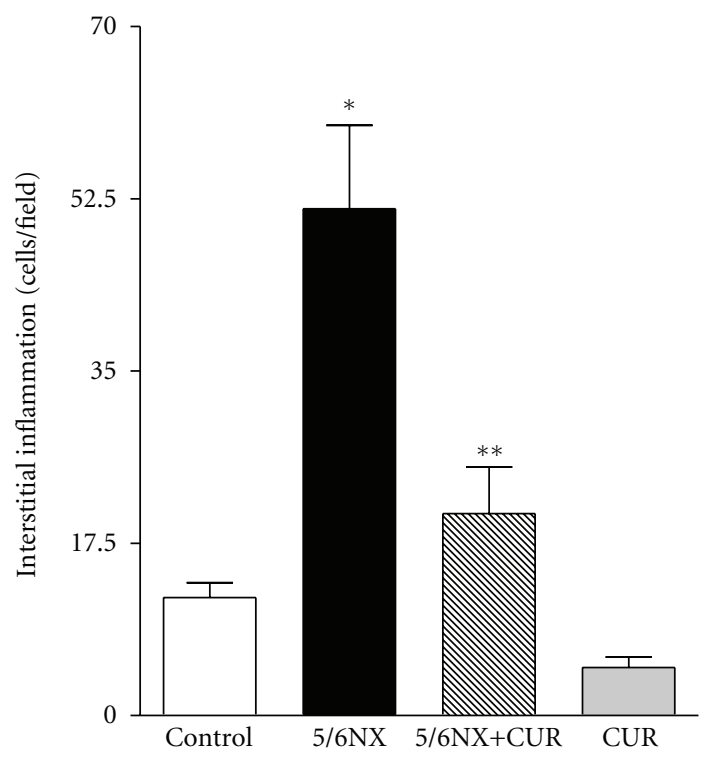

(e)

Figure 5: Curcumin (60 mg/kg/day) ameliorated 5/6NX-induced Interstitial inflammation at the end of the study (day 30). Upper panels shows representative images of the groups studied. 40X. Lower panel show quantitative data. Data are mean \pm SEM of $8-10$ rats. ${ }^{*} P<0.05$ versus control, ${ }^{* *} P<0.05$ versus $5 / 6 \mathrm{NX}$. 


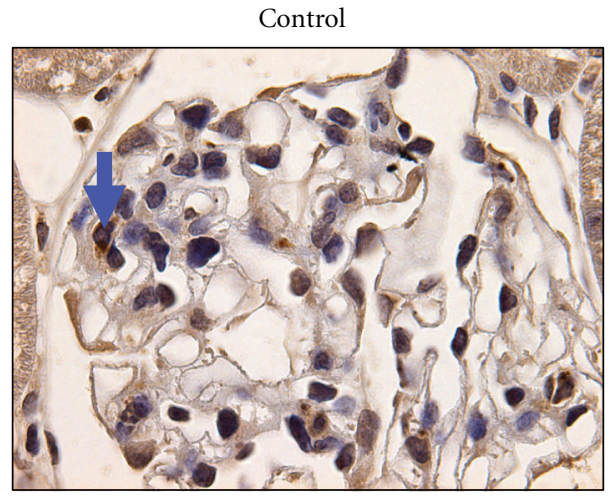

(a)

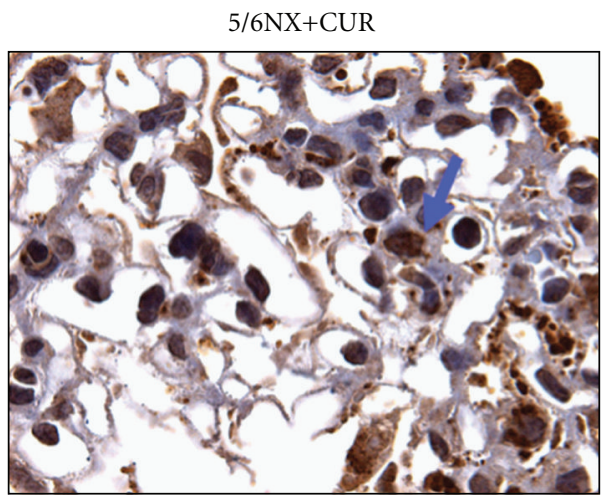

(c)

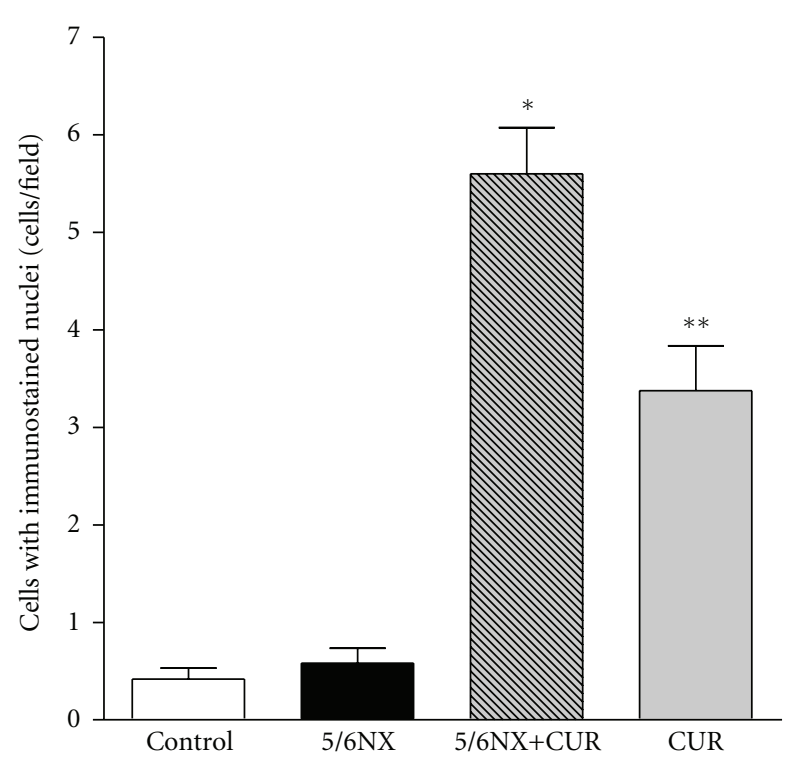

(e)

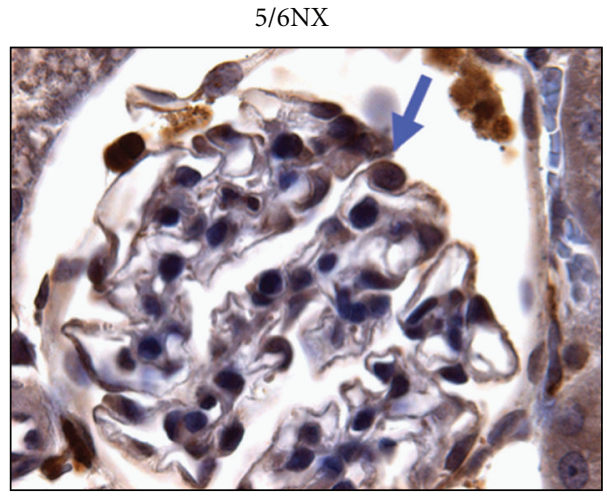

(b)

CUR

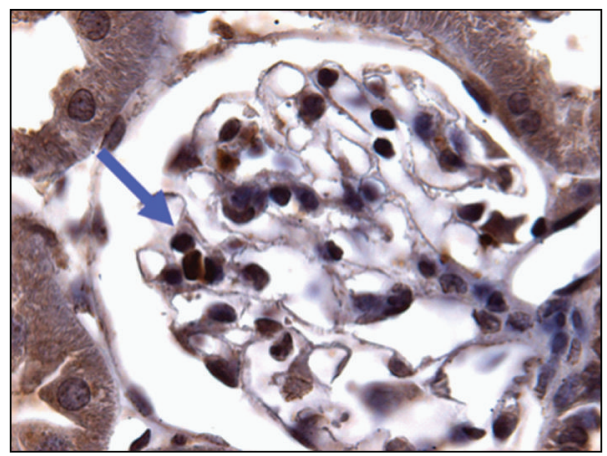

(d)

FIgURE 6: Curcumin $(60 \mathrm{mg} / \mathrm{kg} / \mathrm{day})$ induced nuclear translocation of Nrf2 at the end of the study (day 30). Arrows indicate immunostained nuclei. Upper panels shows representative images of the groups studied. 100X. Lower panel show quantitative data. Data are mean \pm SEM, ${ }^{*} P<0.01$ versus control, ${ }^{* *} P<0.05$ versus $5 / 6$ NX. 


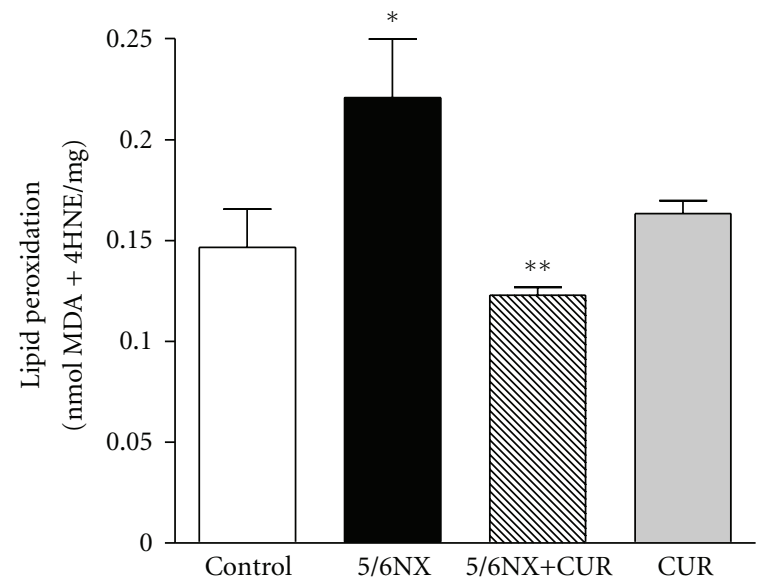

(a)

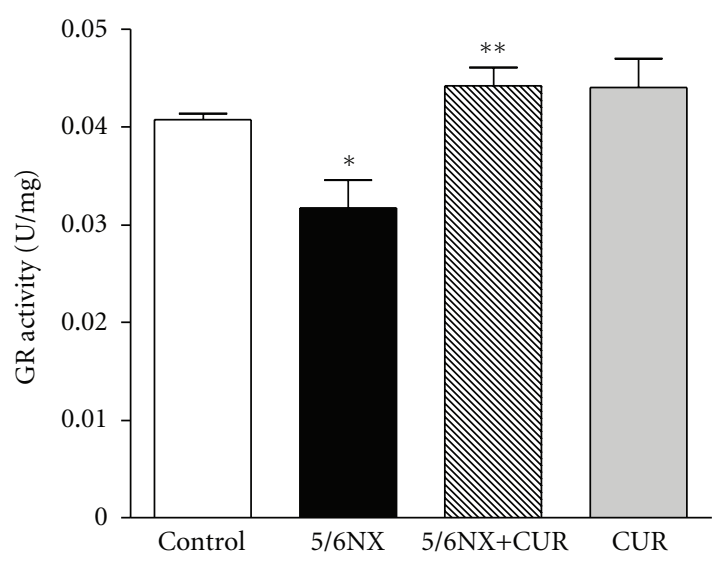

(c)

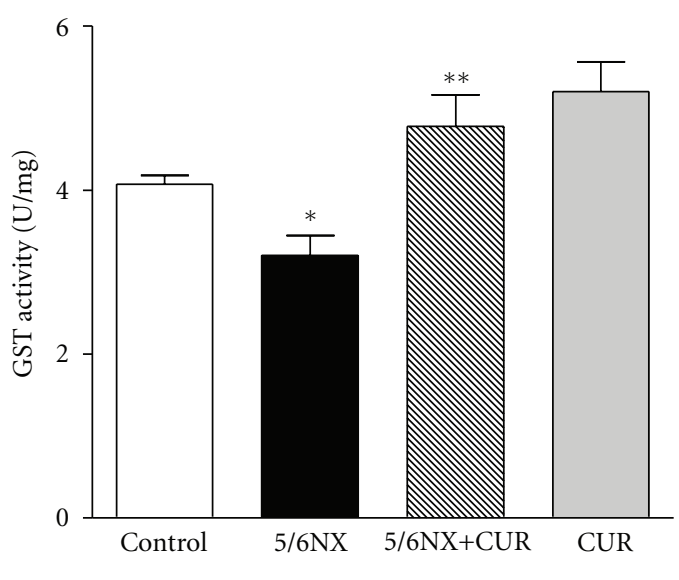

(e)

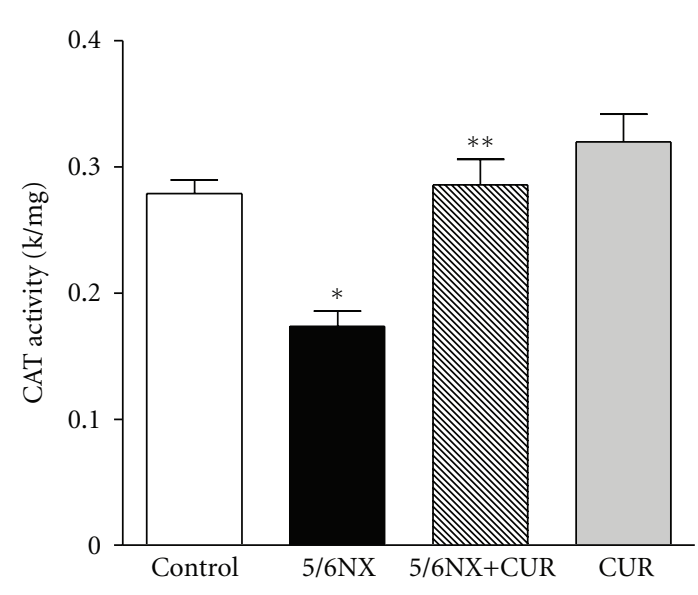

(b)

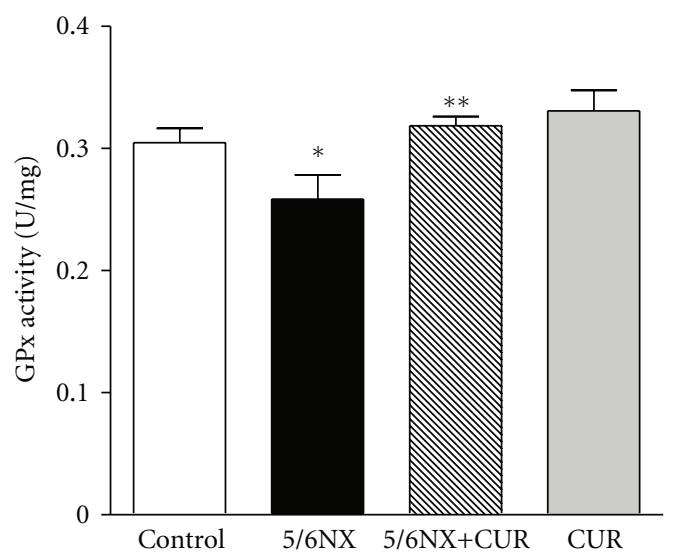

(d)

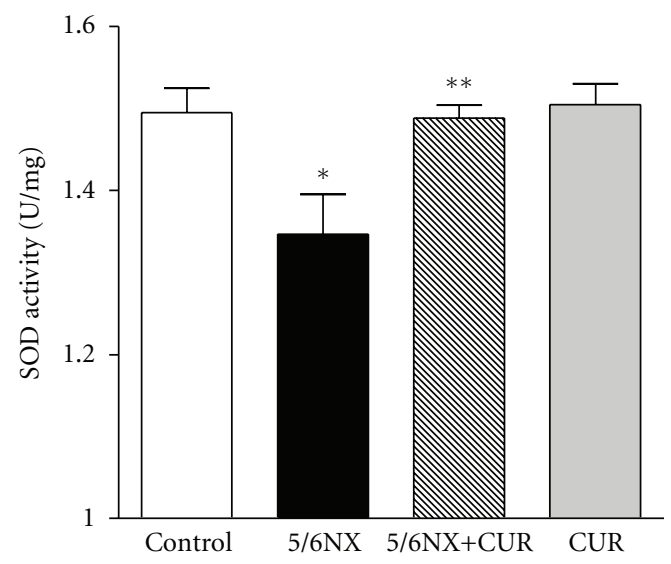

(f)

FIGURE 7: Curcumin $(60 \mathrm{mg} / \mathrm{kg} /$ day $)$ on 5/6NX-induced lipid peroxidation and decrease in the activity of antioxidant enzymes in kidney homogenates. CAT: catalase, GR: glutathione reductase, GPx: glutathione peroxidase, GST: glutathione S-transferase, SOD: superoxide dismutase, MDA: malondialdehyde, 4-HNE: 4-hydroxy-2-nonenal, k: constant first-order reaction, U: international units, mg: milligram of protein. Data represent mean $\pm \mathrm{SEM}, n=6-8 .{ }^{*} P<0.05$ versus control; ${ }^{* *} P<0.01$ versus 5/6NX. 
the protective effect observed. Potential clinical benefits of curcumin therapy deserve further study.

\section{Acknowledgments}

This work was supported by CONACYT 167949 (ET) and 129838 and PAPIIT IN201910 (JPCH). The authors are grateful to Benito Chávez-Rentería and Juan Alfredo Alvarado Cortés for their technical support and to Dr. Ismael Torres and Dr. Enrique Pinzón for the technical assistance with experimental animals.

\section{References}

[1] S. C. Gupta, S. Prasad, J. H. Kim et al., "Multitargeting by curcumin as revealed by molecular interaction studies," Natural Product Reports, vol. 28, no. 12, pp. 1937-1955.

[2] V. Calabrese, T. E. Bates, C. Mancuso et al., "Curcumin and the cellular stress response in free radical-related diseases," Molecular Nutrition and Food Research, vol. 52, no. 9, pp. 1062-1073, 2008.

[3] R. Kannappan, S. C. Gupta, J. H. Kim, S. Reuter, and B. B. Aggarwal, "Neuroprotection by spice-derived nutraceuticals: you are what you eat!," Molecular Neurobiology, vol. 44, no. 2, pp. 142-159, 2011.

[4] S. S. Ghosh, H. D. Massey, R. Krieg et al., "Curcumin ameliorates renal failure in 5/6 nephrectomized rats: role of inflammation," American Journal of Physiology, vol. 296, no. 5, pp. F1146-F1157, 2009.

[5] Y. Fu, S. Zheng, J. Lin, J. Ryerse, and A. Chen, "Curcumin protects the rat liver from CCl4-caused injury and fibrogenesis by attenuating oxidative stress and suppressing inflammation," Molecular Pharmacology, vol. 73, no. 2, pp. 399-409, 2008.

[6] R. R. Satoskar, S. J. Shah, and S. G. Shenoy, "Evaluation of anti-inflammatory property of curcumin (diferuloyl methane) in patients with postoperative inflammation," International Journal of Clinical Pharmacology Therapy and Toxicology, vol. 24, no. 12, pp. 651-654, 1986.

[7] S. Sharma, S. K. Kulkarni, and K. Chopra, "Curcumin, the active principle of turmeric (Curcuma longa), ameliorates diabetic nephropathy in rats," Clinical and Experimental Pharmacology and Physiology, vol. 33, no. 10, pp. 940-945, 2006.

[8] E. Molina-Jijón, E. Tapia, C. Zazueta, and M. E. 1. Hafidi, "Curcumin prevents $\mathrm{Cr}(\mathrm{VI})$-induced renal oxidant damage by a mitochondrial pathway," Free Radical Biology and Medicine, vol. 51, no. 8, pp. 1543-1557, 2011.

[9] O. P. Sharma, "Antioxidant activity of curcumin and related compounds," Biochemical Pharmacology, vol. 25, no. 15, pp. 1811-1812, 1976.

[10] A. González-Salazar, E. Molina-Jijón, F. Correa et al., "Curcumin protects from cardiac reperfusion damage by attenuation of oxidant stress and mitochondrial dysfunction," Cardiovascular Toxicology, vol. 11, no. 4, pp. 357-364, 2011.

[11] M. K. Unnikrishnan and M. N. A. Rao, "Curcumin inhibits nitrogen dioxide induced oxidation of hemoglobin," Molecular and Cellular Biochemistry, vol. 146, no. 1, pp. 35-37, 1995.

[12] G. S. Sidhu, A. K. Singh, D. Thaloor et al., "Enhancement of wound healing by curcumin in animals," Wound Repair and Regeneration, vol. 6, no. 2, pp. 167-177, 1998.

[13] P. S. Negi, G. K. Jayaprakasha, L. J. M. Rao, and K. K. Sakariah, "Antibacterial activity of turmeric oil: a byproduct from curcumin manufacture," Journal of Agricultural and Food Chemistry, vol. 47, no. 10, pp. 4297-4300, 1999.

[14] A. C. P. Reddy and B. R. Lokesh, "Studies on the inhibitory effects of curcumin and eugenol on the formation of reactive oxygen species and the oxidation of ferrous iron," Molecular and Cellular Biochemistry, vol. 137, no. 1, pp. 1-8, 1994.

[15] M. N. Sreejayan, "Nitric oxide scavenging by curcuminoids," Journal of Pharmacy and Pharmacology, vol. 49, no. 1, pp. 105107, 1997.

[16] E. Balogun, M. Hoque, P. Gong et al., "Curcumin activates the haem oxygenase-1 gene via regulation of Nrf2 and the antioxidant-responsive element," Biochemical Journal, vol. 371, no. 3, pp. 887-895, 2003.

[17] A. T. Dinkova-Kostova and P. Talalay, "Direct and indirect antioxidant properties of inducers of cytoprotective proteins," Molecular Nutrition and Food Research, vol. 52, supplement 1, pp. S128-S138, 2008.

[18] S. Boddupalli, J. R. Mein, S. Lakkanna, and D. R. James, "Induction of phase 2 antioxidant enzymes by broccoli sulforaphane: perspectives in maintaining the antioxidant activity of vitamins A, C, and E," Frontiers in Genetics, vol. 3, no. 7, pp. 1-5, 2012.

[19] A. 1. Rojo, O. N. Medina-Campos, P. Rada et al., "Signaling pathways activated by the phytochemical nordihydroguaiaretic acid contribute to a Keap1-independent regulation of Nrf2 stability: role of glycogen synthase kinase-3," Free Radical Biolology and Medicine, vol. 52, no. 2, pp. 473-487, 2012.

[20] E. Kansanen, H. K. Jyrkkänen, and A. L. Levonen, "Activation of stress signaling pathways by electrophilic oxidized and nitrated lipids," Free Radical Biology and Medicine, vol. 52, no. 6, pp. 973-982, 2012.

[21] S. S. Ghosh, H. D. Massey, R. Krieg et al., "Curcumin and enalapril ameliorate renal failure by antagonizing inflammation in 5/6 nephrectomized rats: role of phospholipase and cyclooxygenase," American Journal of Physiology Renal Physiology, vol. 302, no. 4, pp. F439-F454, 2012.

[22] E. Tapia, M. Franco, L. G. Sánchez-Lozada et al., "Mycophenolate mofetil prevents arteriolopathy and renal injury in subtotal ablation despite persistent hypertension," Kidney International, vol. 63, no. 3, pp. 994-1002, 2003.

[23] E. Tapia, L. G. Sanchez-Lozada, V. Soto et al., "Sildenafil treatment prevents glomerular hypertension and hyperfiltration in rats with renal ablation," Kidney and Blood Pressure Research, vol. 35, no. 4, pp. 273-280, 2012.

[24] L. G. Sánchez-Lozada, E. Tapia, J. Santamaría et al., "Mild hyperuricemia induces vasoconstriction and maintains glomerular hypertension in normal and remnant kidney rats," Kidney International, vol. 67, no. 1, pp. 237-247, 2005.

[25] L. G. Sánchez-Lozada, E. Tapia, V. Soto et al., "Effect of febuxostat on the progression of renal disease in 5/6 nephrectomy rats with and without hyperuricemia," Nephron, vol. 108, no. 4, pp. p69-p78, 2008.

[26] S. Anderson, H. G. Rennke, and B. M. Brenner, "Antihypertensive therapy must control glomerular hypertension to limit glomerular injury," Journal of Hypertension, vol. 4, supplement 5, pp. S242-S244, 1986.

[27] C. Cruz, R. Correa-Rotter, D. J. Sánchez-González et al., "Renoprotective and antihypertensive effects of S-allylcysteine in 5/6 nephrectomized rats," American Journal of Physiology, vol. 293, no. 5, pp. F1691-F1698, 2007.

[28] H. J. Kim and N. D. Vaziri, "Contribution of impaired Nrf2-Keap1 pathway to oxidative stress and inflammation in chronic renal failure," American Journal of Physiology, vol. 298, no. 3, pp. F662-F671, 2010. 
[29] A. Zúñiga-Toalá, E. Tapia, C. Zazueta, and F. Correa, "Nordihydroguaiaretic acid pretreatment prevents ischemia and reperfusion induced renal injury, oxidant stress and mitochondrial alterations," Journal of Medicinal Plants Research, vol. 6, no. 15, pp. 2938-2947, 2012.

[30] K. A. Nath, A. J. Croatt, S. Likely, T. W. Behrens, and D. Warden, "Renal oxidant injury and oxidant response induced by mercury," Kidney International, vol. 50, no. 3, pp. 1032 1043, 1996.

[31] A. I. Morales, D. Detaille, M. Prieto et al., "Metformin prevents experimental gentamicin-induced nephropathyby a mitochondria-dependent pathway," Kidney International, vol. 77, no. 10, pp. 861-869, 2010.

[32] C. E. Guerrero-Beltrán, M. Calderón-Oliver, E. MartínezAbundis et al., "Protective effect of sulforaphane against cisplatin-induced mitochondrial alterations and impairment in the activity of $\mathrm{NAD}(\mathrm{P}) \mathrm{H}$ : quinone oxidoreductase 1 and $\gamma$ glutamyl cysteine ligase: studies in mitochondria isolated from rat kidney and in LLC-PK1 cells," Toxicology Letters, vol. 199, no. 1, pp. 80-92, 2010.

[33] M. A. Carvalho Rodrigues, J. L. Rodrigues, N. M. Martins et al., "Carvedilol protects against the renal mitochondrial toxicity induced by cisplatin in rats," Mitochondrion, vol. 10, no. 1, pp. 46-53, 2010.

[34] A. Kuhad, S. Pilkhwal, S. Sharma, N. Tirkey, and K. Chopra, "Effect of curcumin on inflammation and oxidative stress in cisplatin-induced experimental nephrotoxicity," Journal of Agricultural and Food Chemistry, vol. 55, no. 25, pp. 1015010155, 2007.

[35] C. Baylis, W. M. Deen, B. D. Myers, and B. M. Brenner, "Effects of some vasodilator drugs on transcapillary fluid exchange in renal cortex," American Journal of Physiology, vol. 230, no. 4, pp. 1148-1158, 1976.

[36] E. Molina-Jijón, G. Zarco-Márquez, and O. N. MedinaCampos, "Deferoxamine pretreatment prevents $\mathrm{Cr}(\mathrm{VI})$ induced nephrotoxicity and oxidant stress: role of $\mathrm{Cr}(\mathrm{VI})$ chelation," Toxicology, vol. 291, no. 1-3, pp. 93-101, 2012.

[37] W. D. Davidson and M. A. Sackner, "Simplification of the anthrone method for the determination of inulin in clearance studies," The Journal of Laboratory and Clinical Medicine, vol. 62, no. 2, pp. 351-356, 1963.

[38] G. G. Vurek and S. E. Pegram, "Fluorometric method for the determination of nanogram quantities of inulin," Analytical Biochemistry, vol. 16, no. 3, pp. 409-419, 1966.

[39] J. W. Viets, W. M. Deen, J. L. Troy, and B. M. Brenner, "Determination of serum protein concentration in nanoliter blood samples using fluorescamine or o-phthalaldehyde," Analytical Biochemistry, vol. 88, no. 2, pp. 513-521, 1978.

[40] E. Chavez, R. Briones, and B. Michel, "Evidence for the involvement of dithiol groups in mitochondrial calcium transport: studies with cadmium," Archives of Biochemistry and Biophysics, vol. 242, no. 2, pp. 493-497, 1985.

[41] J. Himmelfarb and R. M. Hakim, "Oxidative stress in uremia," Current Opinion in Nephrology and Hypertension, vol. 12, no. 6, pp. 593-598, 2003.

[42] C. S. Lim and N. D. Vaziri, "Iron and oxidative stress in renal insufficiency," American Journal of Nephrology, vol. 24, no. 6, pp. 569-575, 2004.

[43] N. D. Vaziri, "Roles of oxidative stress and antioxidant therapy in chronic kidney disease and hypertension," Current Opinion in Nephrology and Hypertension, vol. 13, no. 1, pp. 93-99, 2004.

[44] N. D. Vaziri and B. Rodríguez-Iturbe, "Mechanisms of disease: oxidative stress and inflammation in the pathogenesis of hypertension," Nature Clinical Practice Nephrology, vol. 2, no. 10, pp. 582-593, 2006.

[45] Y. L. Tain, G. Freshour, A. Dikalova, K. Griendling, and C. Baylis, "Vitamin E reduces glomerulosclerosis, restores renal neuronal NOS, and suppresses oxidative stress in the 5/6 nephrectomized rat," American Journal of Physiology, vol. 292, no. 5, pp. F1404-F1410, 2007.

[46] N. D. Vaziri, M. Dicus, N. D. Ho, L. Boroujerdi-Rad, and R. K. Sindhu, "Oxidative stress and dysregulation of superoxide dismutase and NADPH oxidase in renal insufficiency," Kidney International, vol. 63, no. 1, pp. 179-185, 2003.

[47] M. H. Massola Shimizu, T. M. Coimbra, M. De Araujo, L. F. Menezes, and A. C. Seguro, "N-acetylcysteine attenuates the progression of chronic renal failure," Kidney International, vol. 68, no. 5, pp. 2208-2217, 2005.

[48] Y. Quiroz, A. Ferrebuz, F. Romero, N. D. Vaziri, and B. Rodriguez-Iturbe, "Melatonin ameliorates oxidative stress, inflammation, proteinuria, and progression of renal damage in rats with renal mass reduction," American Journal of Physiology, vol. 294, no. 2, pp. F336-F344, 2008.

[49] B. Rodríguez-Iturbe and G. García-García, "The role of tubulointerstitial inflammation in the progression of chronic renal failure," Nephron, vol. 116, no. 2, pp. C81-C87, 2010.

[50] C. Carmona-Ramirez, A. Santamaría, J. C. Tobón-Velasco, and M. Orozco-Ibarra, "Curcumin restores Nrf2 levels and prevents quinolinic acid-induced neurotoxicity," Journal of Nutritional Biochemistry. In press.

[51] R. Manikandan, M. Beulaja, R. Thiagarajan, A. Priyadarsini, R. Saravanan, and M. Arumugam, "Ameliorative effects of curcumin against renal injuries mediated by inducible nitric oxide synthase and nuclear factor kappa B during gentamicininduced toxicity in Wistar rats," European Journal of Pharmacology, vol. 670, no. 2-3, pp. 578-585, 2011.

[52] S. F. Nabavi, A. H. Moghaddam, S. Eslami, and S. M. Nabavi, "Protective effects of curcumin against sodium fluorideinduced toxicity in rat kidneys," Biological Trace Element Research, vol. 145, no. 3, pp. 369-374, 2012.

[53] M. H. Ahmida, "Protective role of curcumin in nephrotoxic oxidative damage induced by vancomycin in rats," Experimental and Toxicologic Pathology, vol. 64, no. 3, pp. 149-153, 2012.

[54] E. A. Abdel Fattah, H. E. Hashem, F. A. Ahmed, M. A. Ghallab, I. Varga, and S. Polak, "Prophylactic role of curcumin against cyclosporine-induced nephrotoxicity: histological and immunohistological study," General Physiology and Biophysics, vol. 29, no. 1, pp. 85-94, 2010.

[55] M. Cekmen, Y. O. Ilbey, E. Ozbek, A. Simsek, A. Somay, and C. Ersoz, "Curcumin prevents oxidative renal damage induced by acetaminophen in rats," Food and Chemical Toxicology, vol. 47, no. 7, pp. 1480-1484, 2009.

[56] V. Eybl, D. Kotyzová, P. Černá, and J. Koutenský, "Effect of melatonin, curcumin, quercetin, and resveratrol on acute ferric nitrilotriacetate (Fe-NTA)-induced renal oxidative damage in rats," Human and Experimental Toxicology, vol. 27, no. 4, pp. 347-353, 2008.

[57] N. Venkatesan, D. Punithavathi, and V. Arumugam, "Curcumin prevents adriamycin nephrotoxicity in rats," British Journal of Pharmacology, vol. 129, no. 2, pp. 231-234, 2000. 


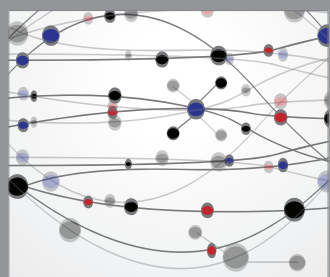

The Scientific World Journal
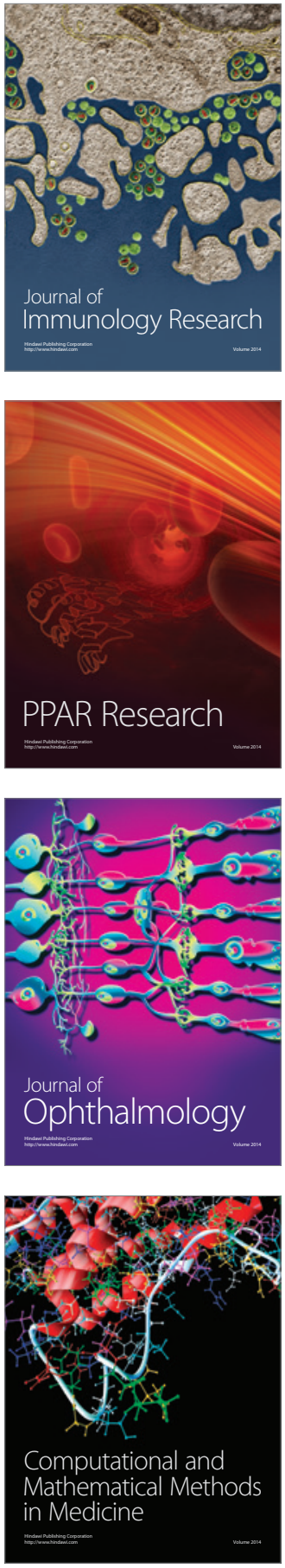

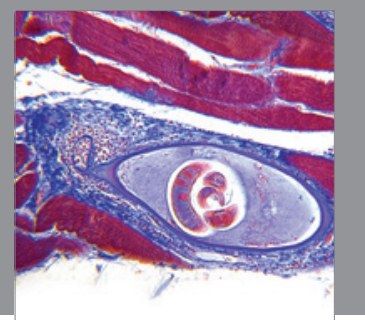

Gastroenterology

Research and Practice
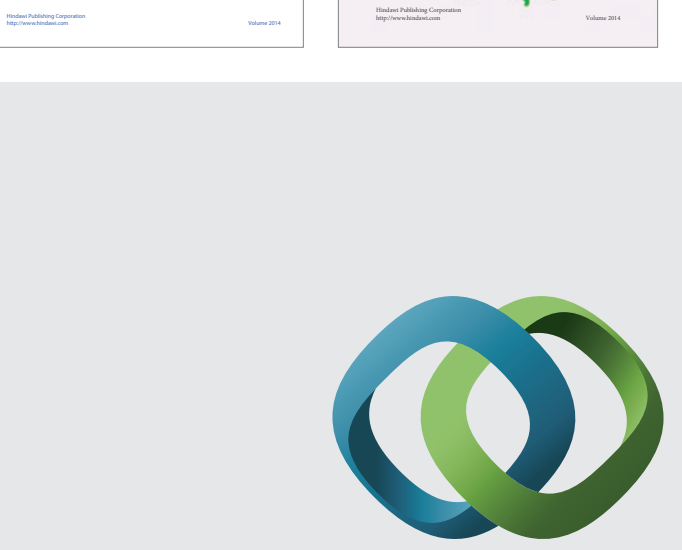

\section{Hindawi}

Submit your manuscripts at

http://www.hindawi.com
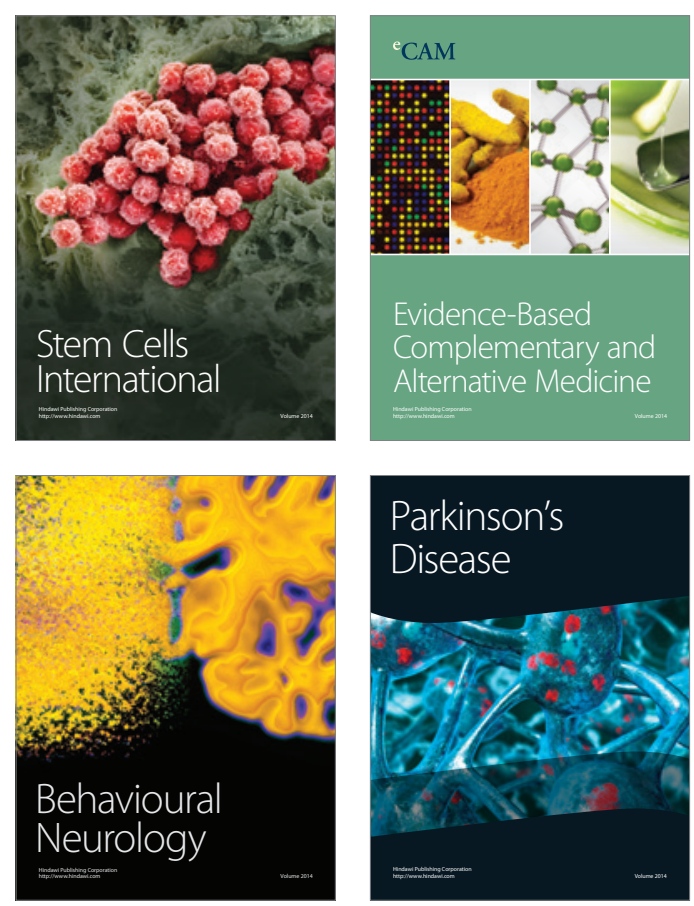

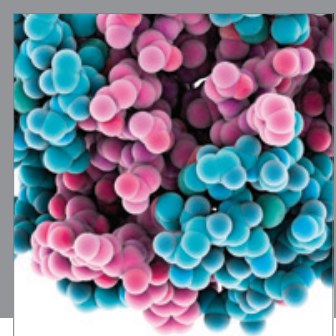

Journal of
Diabetes Research

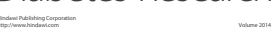

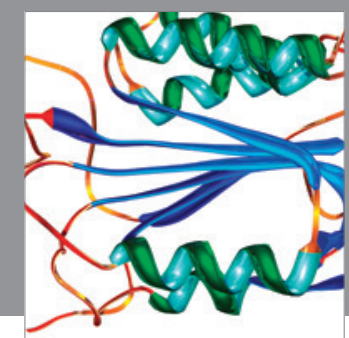

Disease Markers
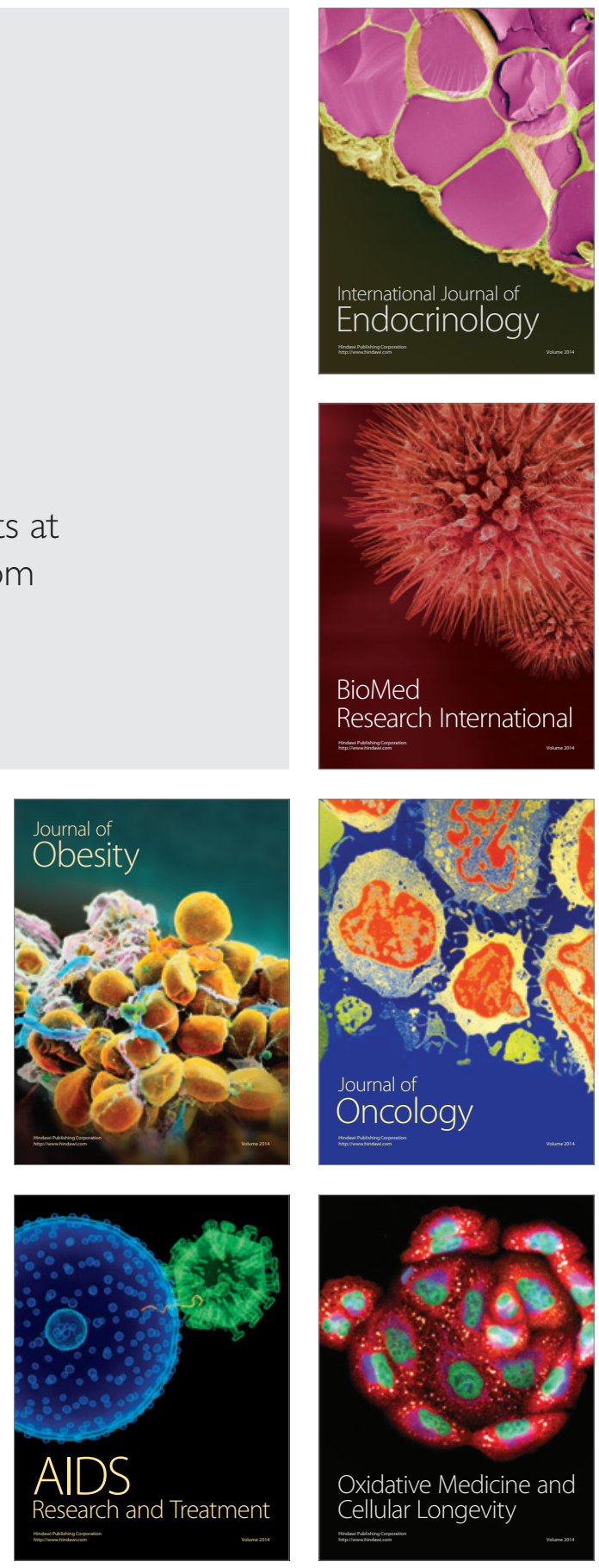